\title{
Studies on ascaridid, oxyurid and enoplid nematodes (Nematoda) from fishes of the Okavango River, Botswana
}

\author{
František Moravec $^{1}$ and Liesl L. Van $\mathbf{A s}{ }^{2}$ \\ ${ }^{1}$ Institute of Parasitology, Biology Centre of the Czech Academy of Sciences, České Budějovice, Czech Republic; \\ ${ }^{2}$ Department of Zoology and Entomology, University of the Free State, Bloemfontein, South Africa
}

\begin{abstract}
Based on light and scanning electron microscopical studies, eight species (five adult and three larval) of nematodes belonging to the Ascaridida, Oxyurida and Enoplida were collected from fishes of the Okavango River, Botswana, namely Falcaustra similis Moravec et Van As, 2004, Atractidae gen. sp. (only female) (both Cosmocercoidea), Cucullanus sp. (only female) (Seuratoidea), Cithariniella longicaudata sp. n., Synodontisia annulata sp. n. (both Oxyuroidea), Contracaecum sp. third-stage larvae, third-stage larvae of Galeiceps sp. (both Ascaridoidea) and Eustrongylides sp. fourth-stage larvae (Dioctophymatoidea). The new species Citharinella longicaudata (type host Schilbe intermedius Rüppel) is mainly characterised by the shape and size of cephalic papillae and the spicule $108 \mu \mathrm{m}$ long, and Synodontisia annulata (type host S. intermedius) by the shape of cephalic papillae, body length of gravid females $(4.88-5.33 \mathrm{~mm})$ and a short spicule $(66 \mu \mathrm{m}$ long). The female specimen of Cucullanus sp. from Tilapia sparmanni Smith markedly differs from congeners parasitising inland fishes in Africa by the elongate pseudobuccal capsule and by the excretory pore far posterior to the oesophago-intestinal junction; apparently, it belongs to an undescribed species. Galeiceps larvae parasitising fishes are described for the first time. Cithariniella gonzalezi Van Waerebeke, Chabaud, Bain et Georges, 1988 is considered a junior synonym of C. khalili Petter, Vassiliadès et Troncy, 1972, and the previous records of Cithariniella citharini Khalil, 1964 from Synodontis spp. in Egypt concern, in fact, Cithariniella khalili Petter, Vassiliadès et Troncy, 1972. The specimens of Cithariniella reported by Koubková et al. (2010) from Paradistichodus dimidiatus (Pellegrin) in Senegal and misidentified as C. gonzalesi Van Waerebeke, Chabaud, Bain et Georges, 1988 are considered to represent a new species, C. koubkovae sp. n.; this is established by reference to the description and drawings provided by Koubková et al. (2010).
\end{abstract}

Keywords: helminth parasites, taxonomy, new species, Cucullanus, Cithariniella, Synodontisia, Galeiceps, freshwater fish, Africa

The fauna of nematode parasites of fishes in Africa remains little known. Recently, Moravec and Van As $(2015 \mathrm{a}-\mathrm{c})$ have published results of their studies on spirurid nematodes (Spirurida) from fishes in the Okavango River, Botswana, based on the materials collected by the team of the junior author (L. L. Van As) during 2001-2003. This paper is a continuation of these studies, based on the same nematode collection, now providing results of the systematic evaluation of nematodes of the orders Ascaridida, Oxyurida and Enoplida. Detailed morphological examinations (using both light and scanning electron microscopy) of these materials revealed the presence of several species, including three new taxa of adults and previously undescribed larvae of a little-known anisakid genus. The results are presented herein.

\section{MATERIALS AND METHODS}

A total of 169 specimens belonging to nine fish species of the families Alestidae, Cichlidae, Clariidae, Mochokidae and Schilbeidae were collected in the Okavango River (mainstream in the Shakawe area) in the Panhandle, by gill nets, cast-nets and electro-fishing. Fish were taken live to a nearby field laboratory and maintained unfed in plastic tanks for at least two days to allow the gut to empty. The fish were anaesthetised and killed using MS222 and the internal organs were removed and placed in 1\% saline. Nematodes removed from the digestive tract and viscera were fixed in $4 \%$ or $10 \%$ buffered neutral formalin.

For light microscopical examination, the nematodes were cleared gradually in glycerine. Drawings were made with the aid of a Zeiss microscope drawing attachment. Specimens used for scanning electron microscopy (SEM) were post-fixed in $1 \%$ osmium tetroxide (in phosphate buffer), dehydrated through a graded ethanol series, critical-point-dried and sputter-coated with gold; they were examined using a JEOL JSM-7401F scanning electron microscope at an accelerating voltage of $4 \mathrm{kV}$ (GB low mode). All measurements are in micrometres unless otherwise indicated. Only small numbers of the available specimens could be used in the descriptions and there is no relationship to the number of infected hosts. Unfortunately, some of the specimens were discarded before they were identified and, consequently,

Address for correspondence: F. Moravec, Institute of Parasitology, Biology Centre of the Czech Academy of Sciences, Branišovská 31 , 370 05 České Budějovice, Czech Republic. Phone +420 38777 5432; Fax: +420 38 5310388; E-mail: moravec@paru.cas.cz

Zoobank number for article: urn:lsid:zoobank.org:pub:DE636137-976F-4D48-A6F8-178E98285F3C 
their species identification is assumed based on the host species at the same locality. Nematodes (except for Dioctophymatoidea) are listed according to the classification system of Anderson et al. (2009). The names of fishes follow FishBase (Froese and Pauly 2015).

\section{RESULTS}

Cosmocercoidea Railliet, 1916

Kathlaniidae Lane, 1914

Falcaustra similis Moravec et Van As, 2004

Figs. 1, 2

Description (based on specimens from Schilbe intermedius Rüppel): Medium-sized, fusiform, whitish nematodes. Cuticle finely transversely striated. Lateral alae absent. Deirids well developed, rounded, situated at about mid-level of oesophagus (Fig. 1A). Oral aperture large, triangular, surrounded by 3 small lips, each bearing 2 cephalic papillae; pair of amphids present (Figs. 1C, 2A). Buccal cavity supported by flat cuticularised ring (Fig. 1B). Oesophagus consists of short, muscular pharyngeal portion, long corpus, inflated isthmus forming pre-bulb, and bulb. Nerve ring encircling oesophageal corpus at about $1 / 4$ of way along its length, excretory pore near level of junction of corpus and pre-bulb. Anterior end of intestine expanded (Fig. 1A). Tail of both sexes conical, sharply pointed.

Male (5 specimens): Length of body $8.85-12.36 \mathrm{~mm}$, maximum width 639-789. Lips 27-36 long; width of cephalic end at level of lips 120-147. Length of entire oesophagus 1.67-1.89 mm; length of pharynx 60-69, of corpus 1.20-1.40 mm, of pre-bulb 129-180, of bulb 231-273; width of pharynx, corpus, pre-bulb and bulb 72-90, 66-99, 99-120 and 228-255, respectively. Nerve ring 408-490, excretory pore $1.35-1.59 \mathrm{~mm}$ and deirids 802-1210 from anterior extremity. Posterior end of body curved ventrally. Caudal alae absent. Ventral precloacal sucker present, situated 1.97-3.02 mm from cloacal aperture; ventral side of body between cloaca and sucker with ca 60-70 pairs of oblique muscle bands (Fig. 1F). Eleven pairs of caudal papillae present: 3 subventral preanal pairs, 1 subventral adanal pair and 7 postanal pairs ( 5 subventral and 2 lateral; posterior lateral pair represents phasmids). One additional unpaired median papilla present on ante-
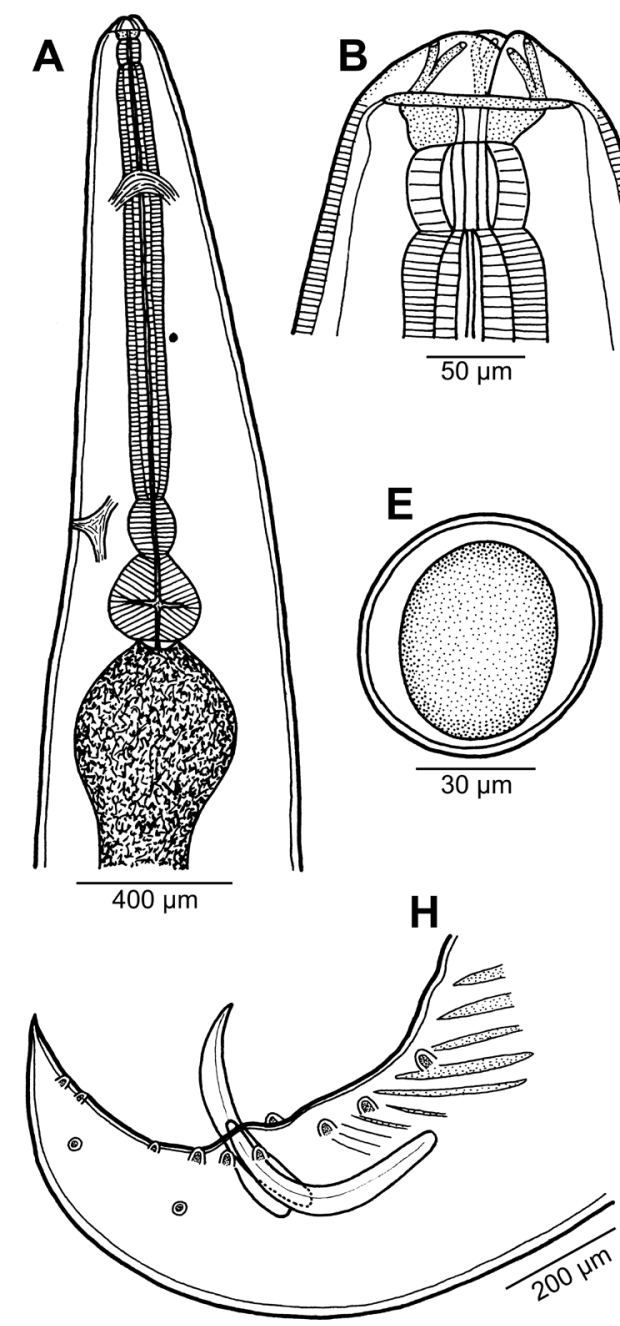
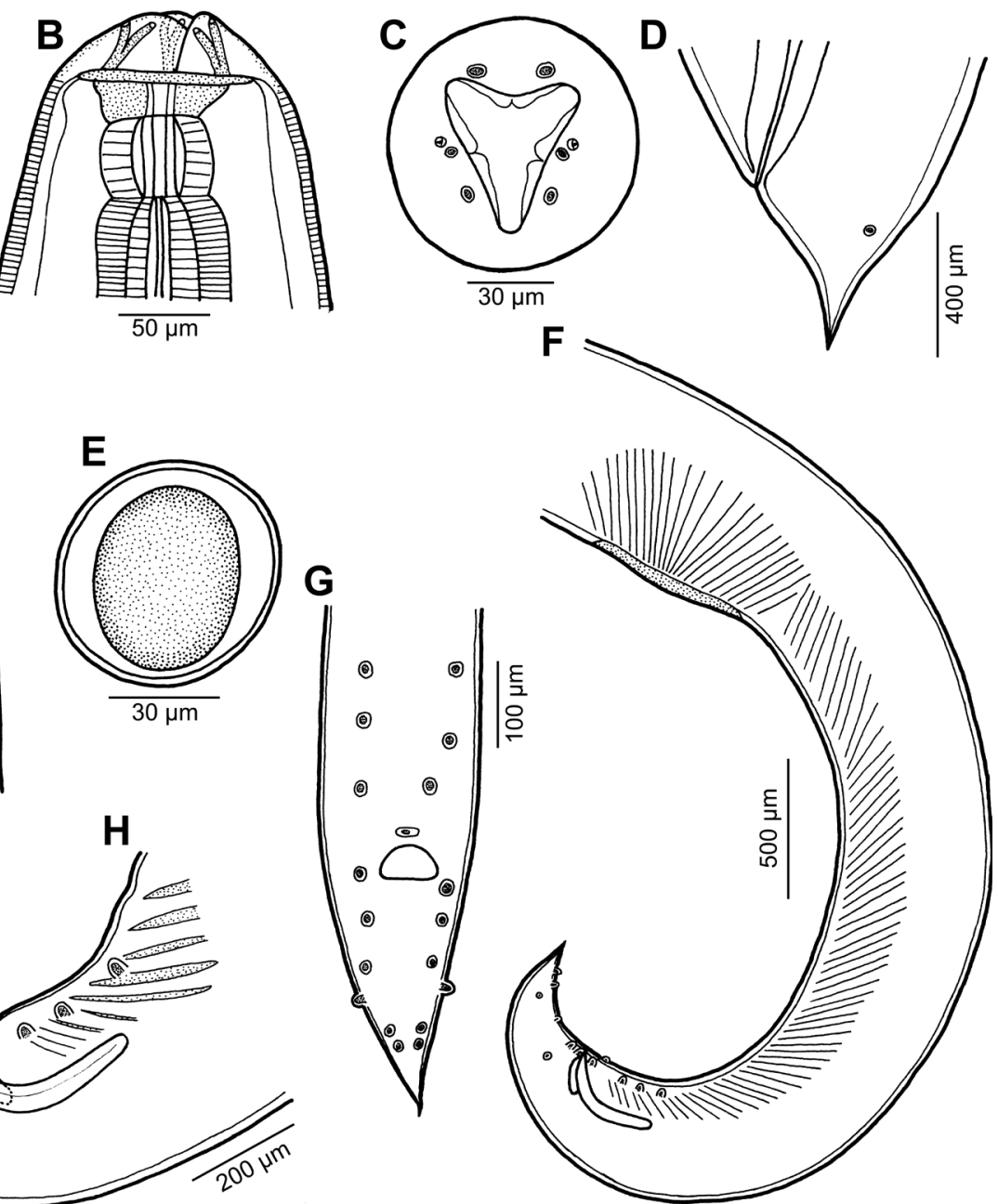

Fig. 1. Falcaustra similis Moravec et Van As, 2004 from Schilbe intermedius Rüppel. A - anterior end of male, lateral view; B, C - cephalic end, lateral and apical views, respectively; D - tail of female, lateral view; $\mathbf{E}$ - egg; $\mathbf{F}, \mathbf{G}$ - posterior end of male, lateral and ventral views; $\mathbf{H}$ - caudal end of male, lateral view. 

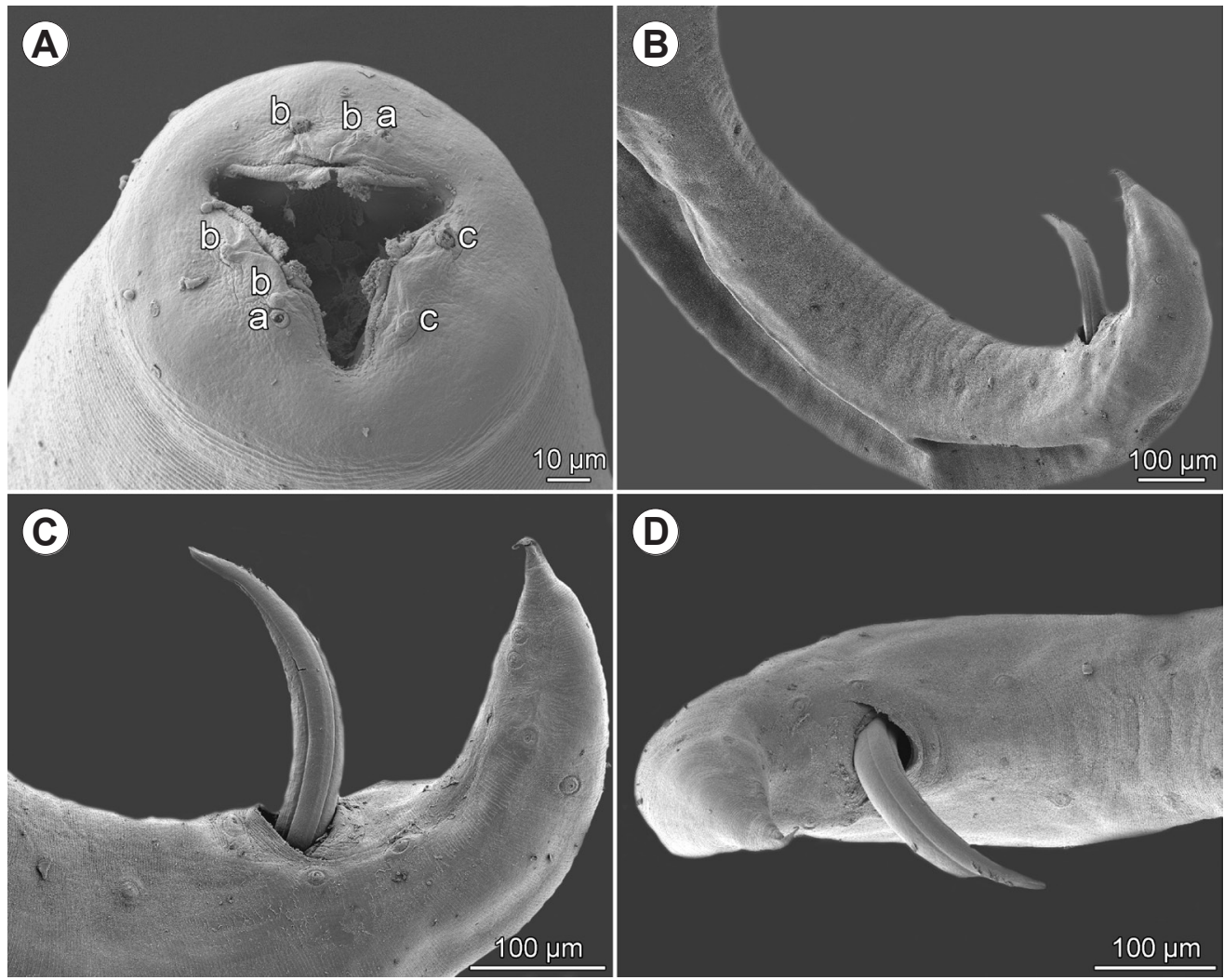

Fig. 2. Falcaustra similis Moravec et Van As, 2004 from Schilbe intermedius Rüppel, scanning electron micrographs. A - cephalic end, apical view; B - posterior end of male, lateral view; C, D - tail of male, lateral and ventral views, respectively. Abbreviations: $\mathrm{a}$ - amphid; $\mathrm{b}$ - subventral or lateral cephalic papilla; $\mathrm{c}$ - submedian dorsal cephalic papilla.

rior cloacal lip (Figs. 1F-H, 2B-D). Spicules equal, alate, slightly curved, 435-530 long (Figs. 1F,H, 2B-D). Gubernaculum well developed, triangular, 132-180 long. Tail 367-530 long.

Female (5 gravid specimens): Length of body 11.06-14.06 mm, maximum width 734-911. Lips 27-39 long; width of cephalic end at level of lips 129-141. Length of entire oesophagus $1.66-1.87 \mathrm{~mm}$; length of pharynx 36-81, of corpus $1.22-1.39 \mathrm{~mm}$, of pre-bulb 144 , of bulb 252-291; width of pharynx, corpus, pre-bulb and bulb 66-90, 99-120, 117-129 and 225-264, respectively. Nerve ring 435-490, excretory pore $1.29-1.63 \mathrm{~mm}$ and deirids 830-1,170 from anterior extremity. Vulva postequatorial, situated 6.96-7.70 mm from anterior extremity (at 52-68\% of body length); vagina muscular, narrow, directed anteriorly from vulva. Eggs numerous, oval, thin-walled, 69-90 $\times 60-66$ (Fig. 1E); content of eggs in uterus uncleaved or cleaved at most into 3 blastomeres. Tail 442-558 long, bearing dorsolateral pair of large phasmids (Fig. 1D).

Hosts: Spotted squeaker, Synodontis nigromaculatus Boulenger, body length $199 \mathrm{~mm}$, S. vanderwaali Skelton et White, body length $200 \mathrm{~mm}$ (both Mochokidae) and silver catfish, Schilbe intermedius Rüppel (Schilbeidae), body length $228 \mathrm{~mm}$ (all Siluriformes).

Site of infection: Intestine.

Locality: Okavango River (Shakawe mainstream 18 26'05"S; 21 54'23"E), Botswana (collected 19 August 2001).

Prevalence: S. nigromaculatus: $26 \%$ (18 fish infected/70 fish examined); S. vanderwaali: 5\% (1/20); S. intermedius: $6 \%$
$(4 / 66)$.

Deposition of voucher specimens: Helminthological Collection of the Institute of Parasitology, Biology Centre of the Czech Academy of Sciences, České Budějovice (Cat. No. N-819).

Remarks. To date, ten species of Falcaustra Lane, 1914 have been described from fishes in Africa: F. guiersi Vassiliadès, 1973, F. hexapapillata (Khalil, 1962), F. petrei (Khalil, 1970), F. piscicola (Linstow, 1907), F. similis Moravec et Van As, 2004, F. straeleni Campana-Rouget, 1961, F. sudanensis (Khalil, 1962), F. tchadi Vassiliadès et Troncy, 1973, F. therezieni Petter, 1979 and F. verbekei Campana-Rouget, 1961 (see Khalil and Polling 1997, Moravec and Van As 2004). Most of them are typically parasites of characiform, cypriniform and perciform fishes (although $F$. therezieni, $F$. guiersi and $F$. straeleni were occasionally also reported from catfishes), whereas $F$. similis is known only from a siluriform host, Synodontis nigromaculatus (Mochokidae).

The nematodes of the present material are morphologically and biometrically very similar to $F$. similis, both forms occur in siluriform hosts in the same locality, and, therefore, they are considered to belong to this species. Small differences in the arrangement of postanal papillae in the male are evidently within the range of intraspecific variabilty, which is usually broad in cosmocercoids. Although one host of these nematodes belongs to a different siluriform family than the type host of $F$. similis (Schilbeidae $v s$ Mochokidae), it is not surprising, because also an- 

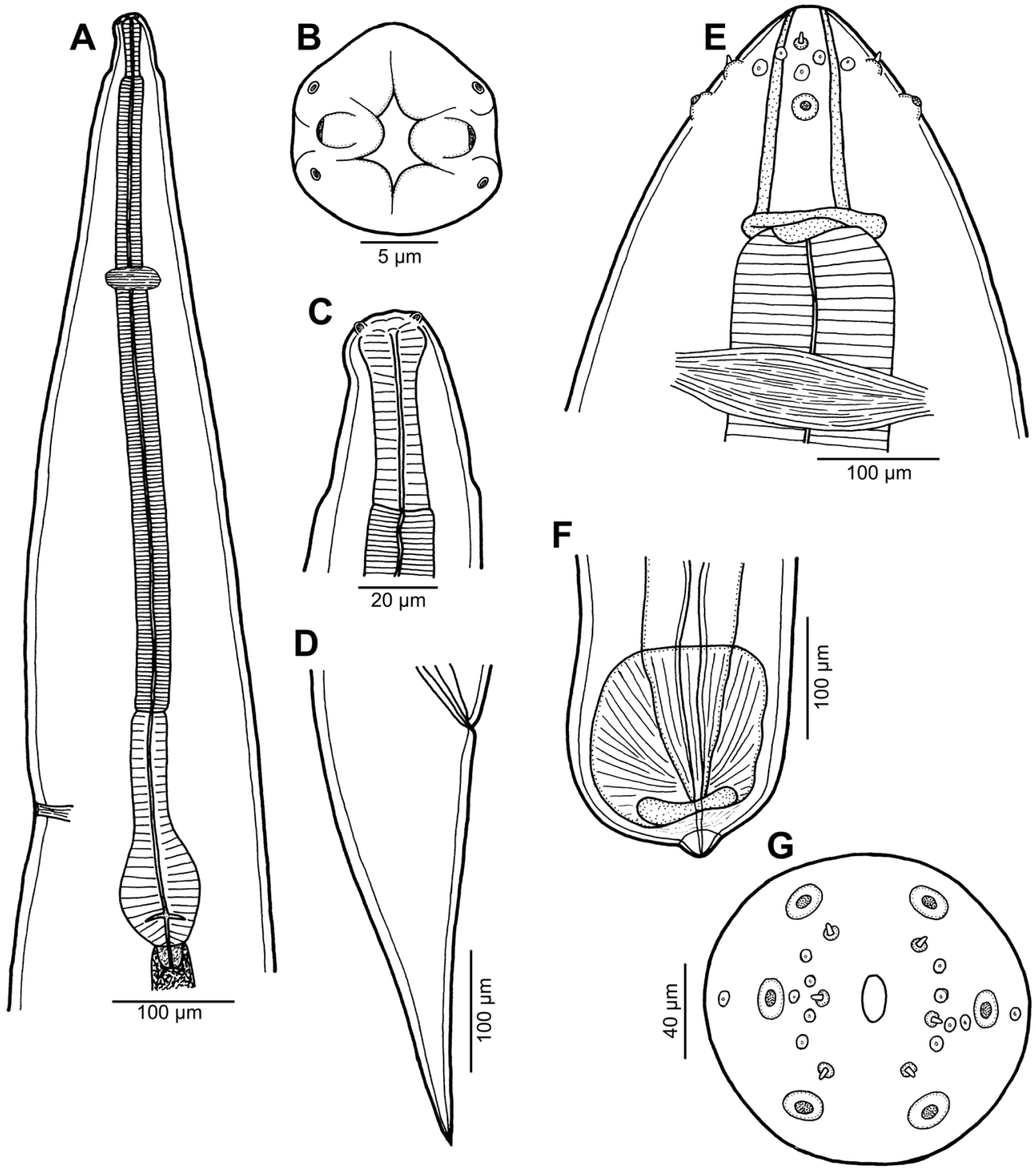

Fig. 3. A-D - Atractidae gen. sp. female from Schilbe intermedius Rüppel (A - anterior end, lateral view; B, C - cephalic end, apical and lateral views, respectively; D - tail, lateral view). E- G - Eustrongylides sp. male fourth-stage larva from Hydrocynus vittatus Castelnau (E - cephalic end, lateral view; $\mathbf{F}$ - caudal end, lateral view; $\mathbf{G}$ - cephalic end, apical view).

other parasite of squeakers (Synodontis spp.), Procamallanus laeviconchus (Wedl, 1861) s. s., has recently been recorded from Schilbe intermedius in Botswana (Moravec and Van As 2015a). The present finding of F. similis in $S$. intermedius represents a new host record.

Atractidae Railliet, 1917

\section{Atractidae gen. sp.}

Figs. 3A-D, 4

Description: Female (1 nongravid specimen): Small, whitish nematode $4.96 \mathrm{~mm}$ long, 299 wide, with finely transversely striated cuticle; very narrow lateral alae arise short distance posterior to anterior extremity, extend posteriorly to about level of anus (Fig. 4A-D). Mouth small, roughly hexagonal, surrounded by 3 bilobed lips. Four small submedian cephalic papillae ( 2 on dorsal lip and 1 on each ventrolateral lip) present; pair of lateral amphids situated on ventrolateral lips (Figs. 3B,C, 4A,B). Oesophagus
840 long; length of short pharyngeal portion 51 , of long corpus 564, of isthmus 114 and of bulb 111; maximum width of pharyngeal portion, corpus, isthmus and bulb 15, 30, 30 and 72, respectively (Fig. 3A). Intestine narrow, straight. Nerve ring somewhat anterior to mid-level of corpus, at 114 from anterior extremity. Excretory pore situated near end of isthmus, at 721 from anterior end of body (Fig. 3A). Deirids not observed. Vulva $1.55 \mathrm{~mm}$ from anterior extremity. Tail conical, shaply pointed, 381 long (Fig. 1D).

Host: Silver catfish, Schilbe intermedius Rüppel (Schilbeidae, Siluriformes), body length $228 \mathrm{~mm}$.

Site of infection: Intestine.

Locality: Okavango River (18²6'05"S; $\left.21^{\circ} 54^{\prime} 23^{\prime \prime E}\right)$, Botswana (collected 19 August 2001).

Prevalence: $1.5 \%$ (1 fish infected/66 fish examined).

Deposition of voucher specimen: Not deposited (used for SEM). 

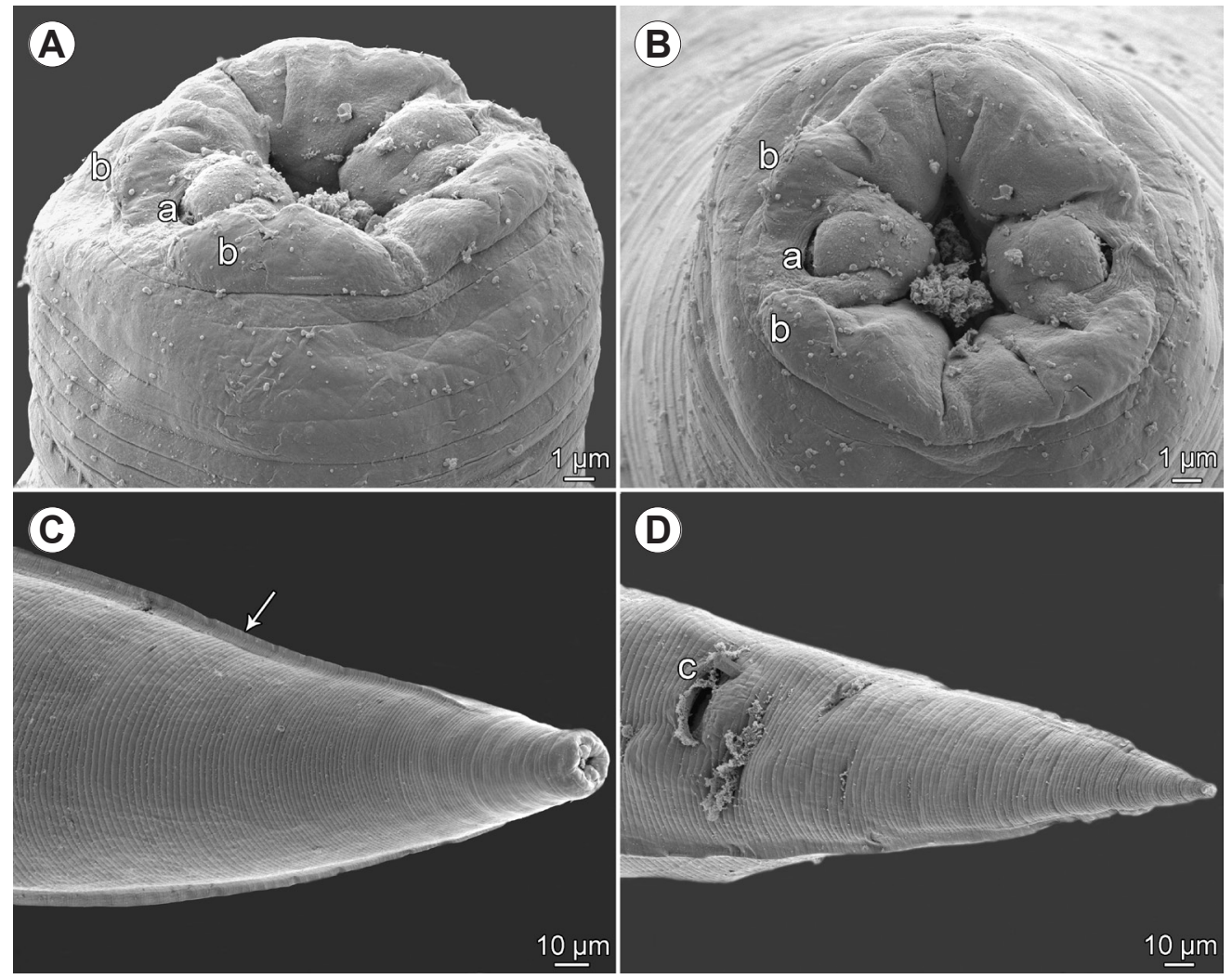

Fig. 4. Atractidae gen. sp. female from Schilbe intermedius Rüppel, scanning electron micrographs. A, B - cephalic end, subventral and apical views; $\mathbf{C}$ - anterior end of body with distinct lateral alae (arrow), ventral view; D - tail, ventral view. Abbreviations: a - amphid; $\mathrm{b}$ - cephalic papilla; $\mathrm{c}$ - anus.

Remarks. Since only a single nongravid female was available, its correct generic identification was impossible. The morphology and measurements of this specimen are very similar to the representatives of Labeonema Puylaert, 1970 (Atractidae), parasites of freshwater fishes in Africa (e.g. Puylaert 1970, Khalil and Polling 1997, Moravec and Van As 2004, Koubková et al. 2008); hosts of the five known species of Labeonema are some cypriniform, characiform and siluriform fishes, including Schilbe mandibularis (Günther), syn. Eutropius liberiensis (Hubrecht), in Gabon for L. bainae Baker, 1982 (see Baker 1982). However, the present specimen differs from Labeonema spp. mainly in the position of the vulva, which is located in the anterior part of the body (at $31 \%$ of the body length), whereas that of Labeonema spp. is in the posterior part.

Seuratoidea Hall, 1916

\section{Cucullanidae Cobbold, 1864}

\section{Cucullanus sp.}

Figs. 5, 6

Description: Female (1 gravid specimen): Mediumsized nematode. Body whitish, elongate, with slightly transversely striated cuticle (Fig. 6G), somewhat narrowed at region just posterior to oesophastome in dorsoventral view (Fig. 5A,B); length of body $14.8 \mathrm{~mm}$; maximum with 462 ; width at region of oesophastome 272, at region of middle of oesophagus 354. Lateral alae absent. Cephalic end somewhat asymmetrical in lateral view. Oral aperture dorsoventrally elongate, surrounded by raised narrow membranous ala (collarette) supported by row of minute basal teeth (Figs. 5C-E, 6A-C,E,F). Four submedian cephalic papillae and pair of lateral amphids present (Figs. 5D, 6A-C). Oesophagus muscular, somewhat expanded at anterior end to form rather large, elongate pseudobuccal capsule (oesophastome); posterior part of oesophagus also expanded, slightly narrower than pseudobuccal capsule (Fig. 5A,B); length of entire oesophagus $1.54 \mathrm{~mm}$, representing $10 \%$ of body length; length of oesophastome 394 , its width 245 ; minimum width of oesophagus 111; maximum width of posterior part of oesophagus 225. Oesophagus opens into intestine through large valve. Distance from nerve ring to anterior extremity 612 , representing $40 \%$ of oesophageal length. Deirids small, rounded, situated slightly posterior to level of oesophago-intestinal junction, at $1.70 \mathrm{~mm}$ from anterior extremity (Figs. 5A,B,F, 6G). Postdeirids not found. Excretory pore far posterior to level of deirids, at 2.04 $\mathrm{mm}$ from anterior end of body. Vulva postequatorial, 9.49 $\mathrm{mm}$ from anterior extremity, at $64 \%$ of body length; vulval lips not elevated (Fig. 5G). Vagina directed anteriorly from vulva. Uteri opposed. Fully developed eggs slightly oval, thin-walled, with markedly granular surface and uncleaved contents (Fig. 5I,J); eggs 105-120 long, 78-90 wide. Tail conical, 490 long, with sharply pointed tip and with pair of small lateral phasmids at middle (Figs. 5H, $6 \mathrm{D})$. 

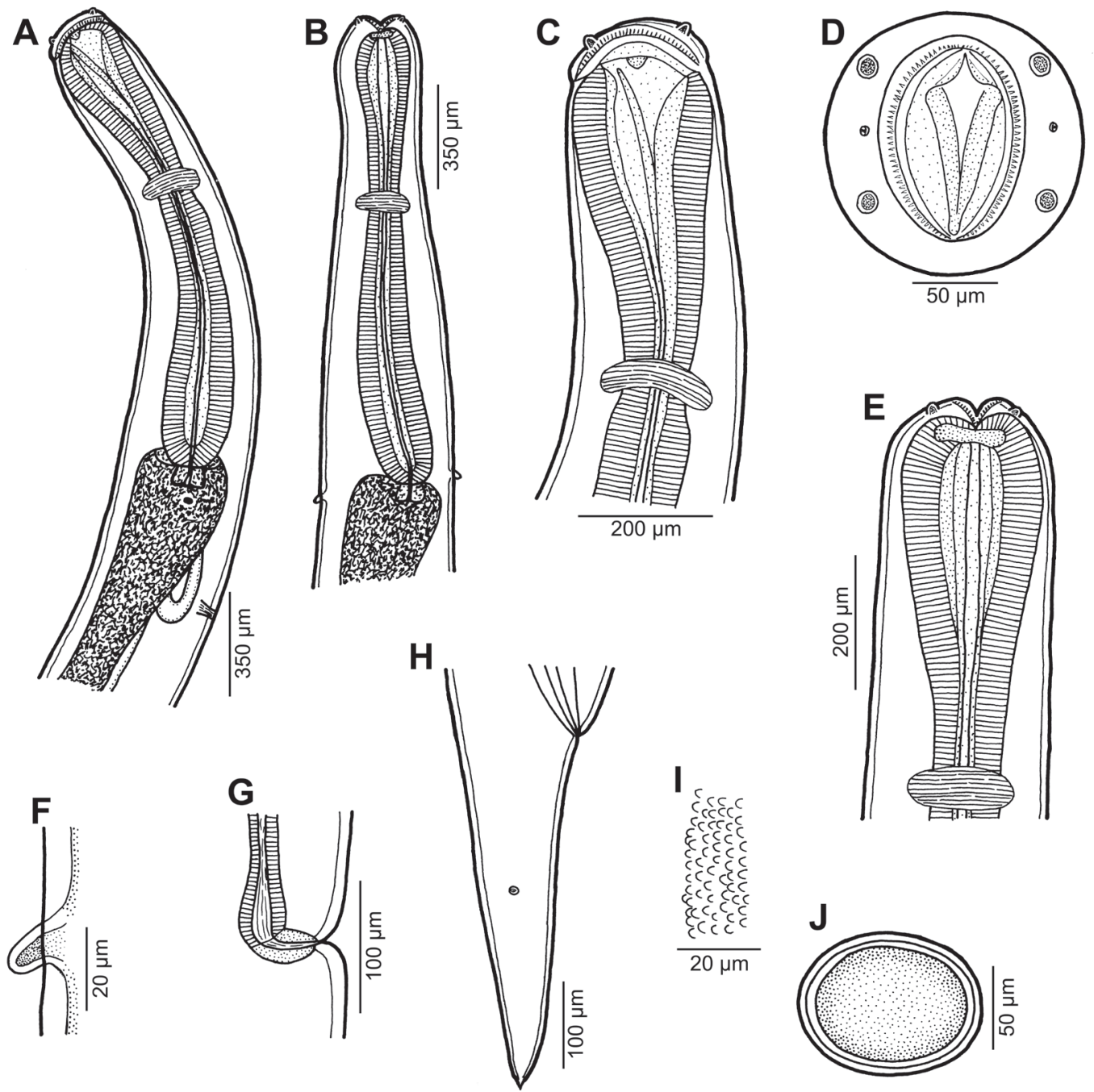

Fig. 5. Cucullanus sp. female from Tilapia sparmanni Smith. A, B - anterior end of body, lateral and dorsoventral views, respectively; $\mathbf{C}$ - oesophastome, lateral view; D - cephalic end, apical view; $\mathbf{E}$ - oesophastome, dorsoventral view; $\mathbf{F}$ - deirid, lateral view; $\mathbf{G}$ - vulva, lateral view; $\mathbf{H}$ - tail, lateral view; I - sculpture of egg surface; J - egg.

Host: Banded tilapia, Tilapia sparmanni Smith (Cichlidae, Perciformes), body length $150 \mathrm{~mm}$.

Site of infection: Intestine.

Locality: Okavango River (Samochima lagoon 18²5'48.9"S; 21 ${ }^{\circ} 53^{\prime} 41.8^{\prime \prime E}$ ), Botswana (collected 11 December 2003).

Prevalence: 1 fish infected $/ 4$ fish examined.

Deposition of voucher specimen: Helminthological Collection of the Institute of Parasitology, Biology Centre of the Czech Academy of Sciences, České Budějovice (Cat. No. N-1083).

Remarks. The genus Cucullanus Müller, 1777 includes a large number of species parasitising freshwater, brackishwater or marine fishes and, less frequently, aquatic turtles. Because of their rather uniform morphology and the inadequate descriptions of many nominal species, it is practically impossible to make a detailed comparison between all of them. Cosequently, some authors prefer to deal with these parasites according to their zoogeographical region or their host groups (see e.g. Yooyen et al. 2011 for respective citations). Therefore, considering the exclusiveness of the fauna of fish nematodes in the Ethiopian Region in Africa, the present nematode specimen from $T$. sparmanni should be principally compared with the species of $\mathrm{Cucul}$ lanus parasitic in African freshwater fishes.

To date, three species of Cucullanus have been described from African freshwater fishes: Cucullanus barbi Baylis, 1923 parasitising Barbus spp. (Cyprinidae) in the Sudan and Egypt (Baylis 1923a, Moravec 1974, Amin 1978, ElNaffar et al. 1983); C. baylisi Campana-Rouget, 1961 from Synodontis spp. (Mochokidae) in the Sudan, the Democratic Republic of the Congo and Chad (Baylis 1923a, Campana-Rouget 1961, Khalil 1969, Vassiliadès and Troncy 1974, Černotíková et al. 2011; including records of specimens from $S$. schall misidentified as C. clarotis Baylis, 1923 by Baylis 1923a and Khalil 1969); and C. clarotis from Clarotes laticeps (Rüppel) (Claroteidae) in the Sudan (Baylis 1923a). Al-Bassel (2003) also reported Cucullanus barbi Paperna, 1964 (a homonym to and probably identical with C. barbi Baylis, 1923 - see Moravec 1974) from Mormyrus kannume Forsskål (Mormyridae) in Egypt, but this identification is questionable.

In addition, two congeneric species, $C$.djilorensis Ndew, Diouf, Bâ et Morand, 2014 and C. egyptae Abdel-Ghaffar, Bashtar, Abdel-Gaber, Morsy, Mehlhorn, Al Quraishy et 

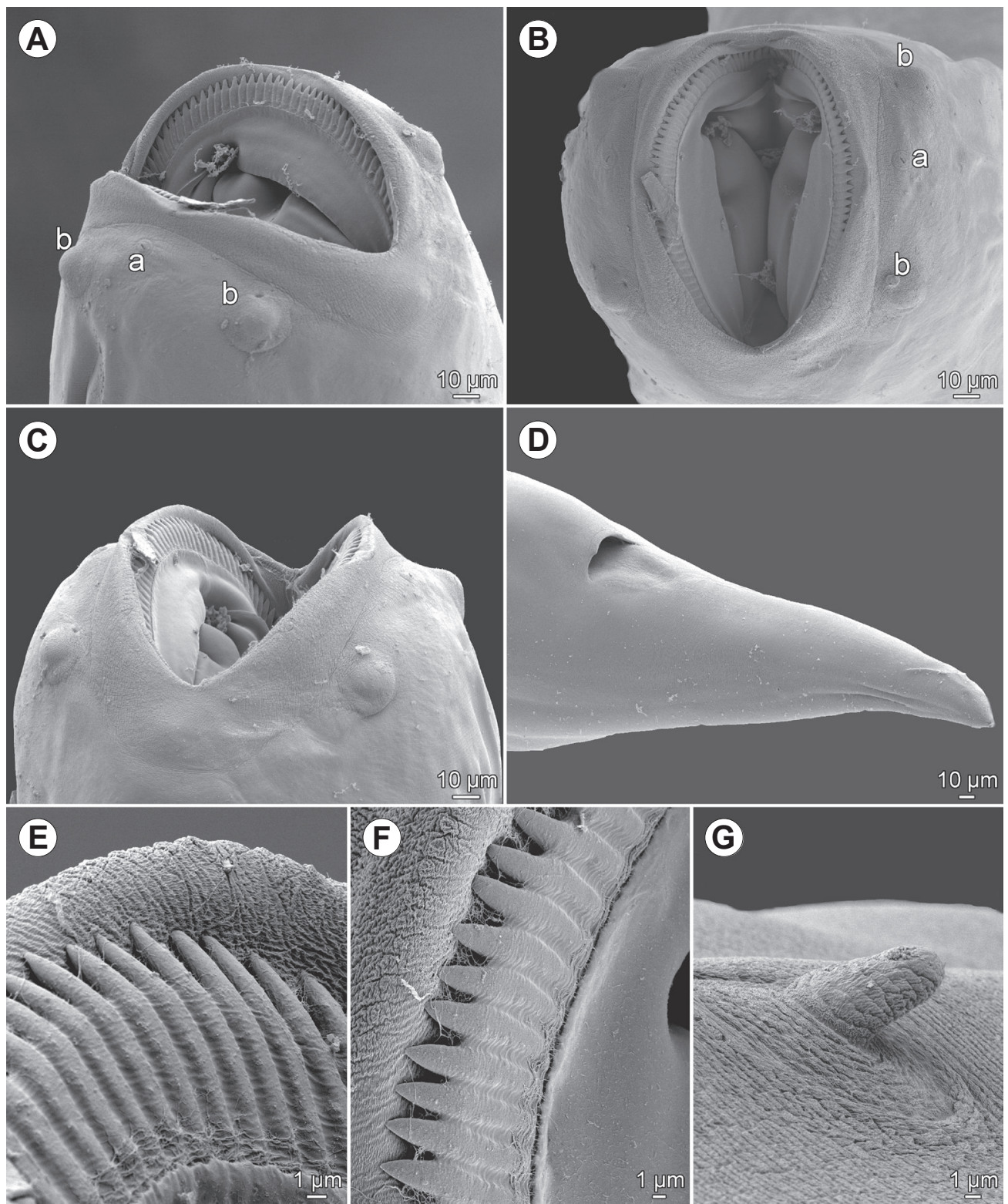

Fig. 6. Cucullanus sp. female from Tilapia sparmanni Smith, scanning electron micrographs. A-C - cephalic end, sublateral, apical and ventral views, respectively; D - tail, ventrolateral view; E, F - circumoral denticles in different views; G - deirid. Abbreviations: $\mathrm{a}$ - amphid; $\mathrm{b}$ - cephalic papilla.

Mohammed, 2014, have recently been described from the estuarine fish Mugil curema Valenciennes (Mugilidae) in Senegal (Ndew et al. 2014) and the European eel Anguilla anguilla (Linnaeus) in the Gulf of Suez (Red Sea, Egypt) (Abdel-Ghaffar et al. 2014), respectively.

Even though the conspecific male of Cucullanus sp. of the present material remains unknown, the available female can be easily distinguished morphologically from all of the above-mentioned species of Cucullanus by the distinctly elongate pseudobuccal capsule and, especially, by the location of deirids at approximately the level of the oesophago-intestinal junction and the excretory pore far posterior to this junction. In contrast, both the excretory pore and deirids are located much more anteriorly, at the oesophageal part of the body, in C. barbi, C. baylisi, C. clarotis and $C$. djilorensis; the excretory pore and deirids were not described for $C$. egyptae, but this poorly described spe- cies can be distinguished from Cucullanus sp. by the cospicuously wide and short pseudobuccal capsule, similar to those in $C$. barbi, $C$. baylisi and $C$. djilorensis (the shape of the pseudobuccal capsule was neither described nor illustrated for $C$. clarotis). Moreover, the roughly granular surface of eggs, as observed in Cucullanus sp., was not described for any of these species. Since this Cucullanus sp. also differs from other African congeners in the host order (Perciformes vs Anguilliformes, Cypriniformes, Mugiliformes and Siluriformes), it is apparent that it represents a hitherto undescribed species.

Two species of Cucullanus, morphologically somewhat similar to the present African Cucullanus sp., were described from fishes of the same family Cichlidae in Mexico: $C$. angeli Cabañas-Carranza et Caspeta-Mandujano, 2007 from Vieja intermedia (Günther) and C. oaxaquensis Caspeta-Mandujano, Salgado-Maldonado et Martínez- 

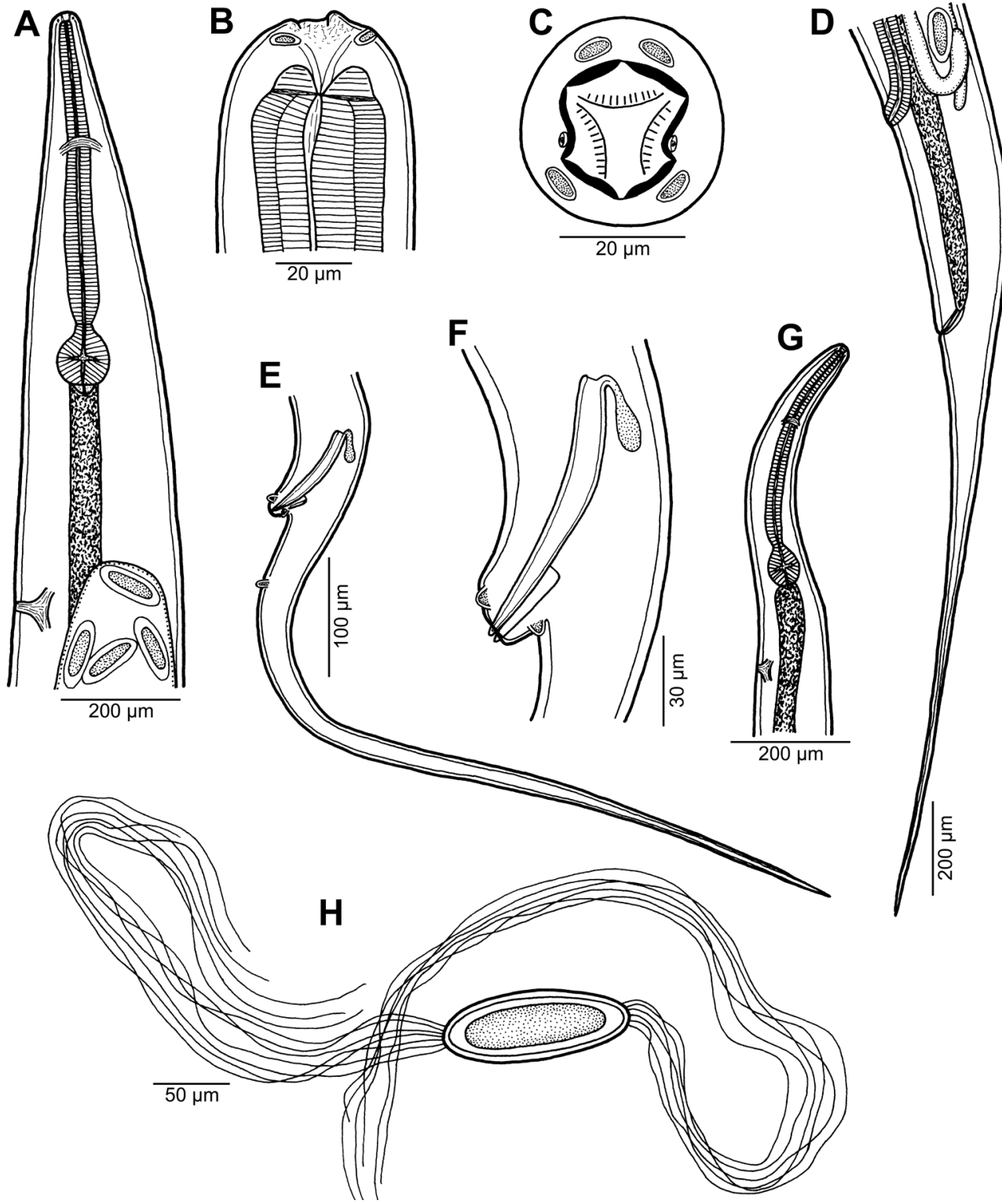

Fig. 7. Cithariniella longicaudata sp. n. from Schilbe intermedius Rüppel. A - anterior end of female, lateral view; B, C - cephalic end of female, lateral and apical views, respectively; $\mathbf{D}$ - posterior end of female, lateral view; $\mathbf{E}$ - posterior end of male, lateral view; $\mathbf{F}$ - region of cloaca, lateral view; $\mathbf{G}$ - anterior end of male, lateral view; $\mathbf{H}$ - egg.

Ramírez, 2010 from Thorichthys helleri Steindachner (see Cabañas-Carranza and Caspeta-Mandujano 2007, Caspeta-Mandujano et al. 2010). It is interesting that the former species has unusually rounded deirids and the latter species possesses eggs with a roughly granular surface, the features that are found in the present Cucullanus sp. However, in contrast to the African Cucullanus sp., C. angeli has the excretory pore and deirids located much more anteriorly, whereas C. oaxaquensis possesses pointed deirids. Moreover, both of these species occur in a different zoogeographical region.

By the shape of the pseudobuccal capsule and the posteriorly located excretory pore and deirids, the present $\mathrm{Cu}$ cullanus sp. n. is also similar to C. bourdini Petter et Le Bel, 1992, a parasite of marine (mainly perciform) fishes off New Caledonia and French Polynesia (Petter and Le Bel 1992, Morand and Rigby 1998, Moravec and Justine 2011). However, both species can be distinguished by the shape of deirids (rounded in the former species $v s$ sharply pointed in the latter), egg surface (roughly granular vs smooth), environment (freshwater $v s$ marine) and the host family (Cichlidae vs mainly Lutjanidae).

\section{Oxyuroidea Cobbold, 1864}

Pharyngodonidae Travassos, 1919

Cithariniella longicaudata sp. n.

Figs. 7, 8

ZooBank number for species:

urn:1sid:zoobank.org:act:D88C3026-6066-4F8B-95AD-91A61BF68843

Description: Small, whitish nematodes with very long, slender tail and fine transverse striation of cuticle in cervical and middle part of body. Lateral alae not observed. Oral aperture roughly triangular, surrounded by 3 lip-like struc- 

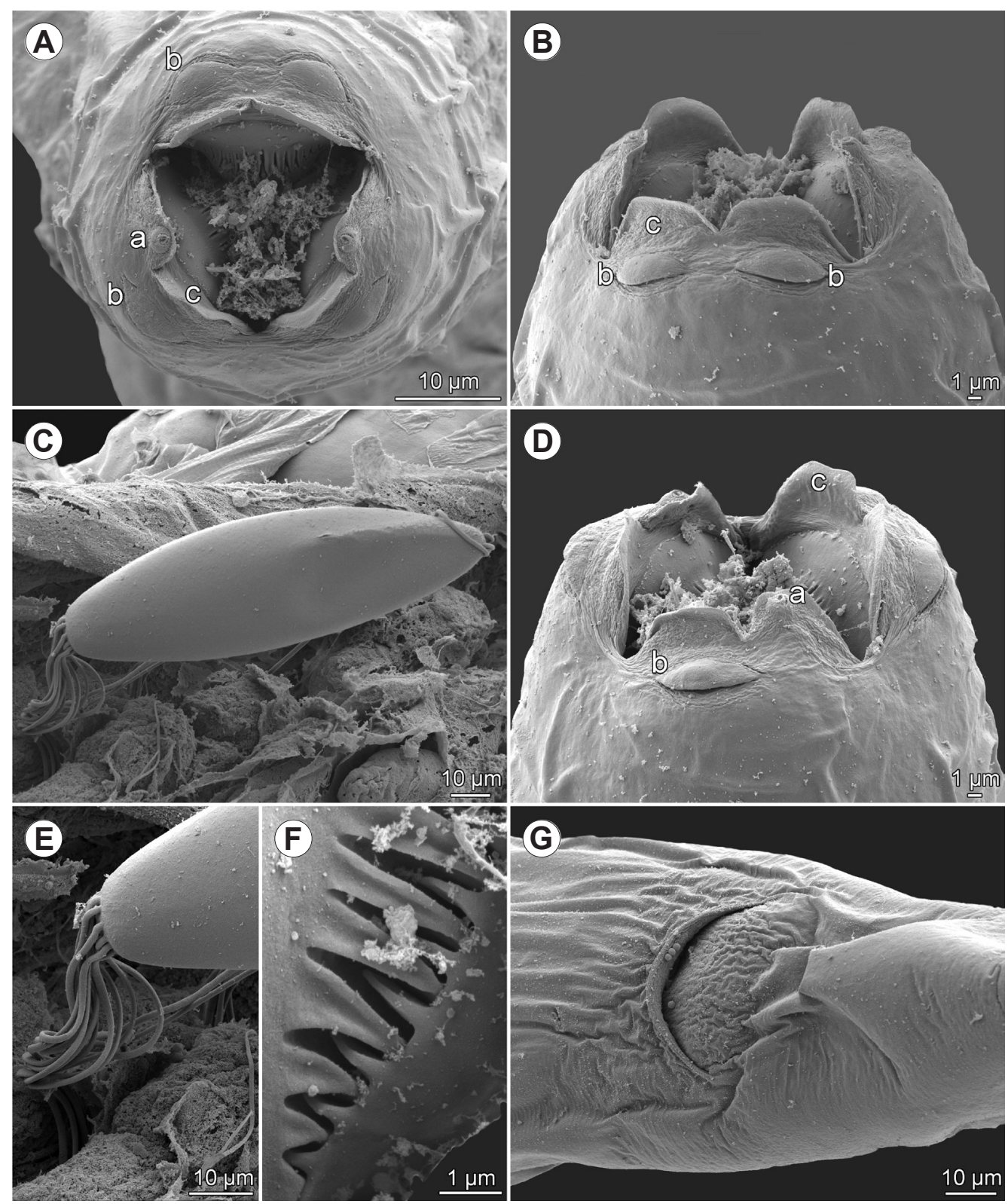

Fig. 8. Cithariniella longicaudata sp. n. female from Schilbe intermedius Rüppel, scanning electron micrographs. A, B - cephalic end, apical and dorsal views, respectively; C - egg; D - cephalic end, sublateral view; $\mathbf{E}$ - egg pole with filaments; $\mathbf{F}$ - tooth-like structures in buccal cavity; $\mathbf{G}$ - region of anus, ventral view. Abbreviations: a - amphid; b - cephalic papilla; c - mouth lamella.

tures provided with 6 oral lamellae (sublabia) (2 dorsolateral and 4 ventrolateral) protruding out of mouth, 4 oval cephalic papillae and pair of lateral amphids (Figs. 7C, $8 \mathrm{~A}, \mathrm{~B}, \mathrm{D})$. Buccal cavity shallow, with 3 sclerotised longitudinal flaps, each of them with longitudinal tooth-like structures (Figs. 7C, 8A,F). Oesophagus cylindrical, almost uniform in diameter, ending in globular bulb provided with valvular apparatus and separated from corpus by constriction (isthmus) (Fig. 7A,G). Intestine straight, narrow. Excretory pore situated relatively far below level of bulb (Fig. 7A,G).

Male (1 specimen): Length of body $2.88 \mathrm{~mm}$, maximum width 150. Buccal cavity 12 long. Entire oesophagus 477 long; length of corpus 369 , width 24 , length of isthmus 21 , width 118 , length of bulb 75 , width 63 . Nerve ring and excretory pore 189 and 441-625, respectively, from anterior extremity. Spicule narrow,108 long, with pointed distal tip; its capitulum 27 long (Fig. 7E,F). Gubernaculum less sclerotised, 36 long. Region of cloacal opening elevated, bearing 2 pairs ( 1 preanal and 1 postanal) of subventral papillae (Fig. 7E,F). Single large median postanal papilla situated 69 posterior to cloacal aperture (at $11 \%$ of length of tail) and 540 from end of tail. Ventral precloacal pseudosucker indistinct. Tail conical, attenuated, 609 long, representing $21 \%$ of body length (Fig. $7 \mathrm{E}$ ).

Female (4 gravid specimens): Length of body 4.11-5.44 mm, maximum width 204-340. Length of buccal cavity 18. Entire oesophagus 644-718 long; length of corpus 503-571, width 445 , length of isthmus 12 , width 30 , length of bulb 111-117 long and 105-108 wide. Nerve ring and excretory pore 233-240 and 857-1 115, respectively, from anterior extremity. Anterior ovary somewhat 
posterior to bulb, posterior ovary attaining level of vulva. Vulva situated 2.48-3.45 mm from anterior extremity (at 59-63\% of body length), 490-694 anterior to anus; vulval lips not elevated (Fig. 7D). Vagina muscular, directed anteriorly from vulva. Uterus filled with many eggs. Eggs elongate, thin-walled, not yet embryonated, provided at each pole with about 10-12 thread-like filaments $c a 500$ long; eggs 135-144 long, 42-48 wide (Figs. 7H, 8C,E). Tail $1.21 \mathrm{~mm}$ long, representing $22-29 \%$ of body length (Figs. 7D, 8G).

Type host: Silver catfish, Schilbe intermedius Rüppel (Schilbeidae), body length $270 \mathrm{~mm}$.

Site of infection: Intestine.

Type locality: Okavango River (Shakawe mainstram $18^{\circ} 26^{\prime} 05^{\prime \prime S} ; 21^{\circ} 54^{\prime} 23^{\prime \prime E}$ ), Botswana (collected 19 August 2001).

Prevalence: $1.5 \%$ (1 fish infected/66 fish examined).

Deposition of type specimens: Helminthological Collection of the Institute of Parasitology, Biology Centre of the Czech Academy of Sciences, České Budějovice (Cat. No. N-1084).

Etymology: The specific name longicaudata (= long-tailed) is the Latin adjective relating to the length of tail of this nematode.

Remarks. To date, the genus Cithariniella Khalil, 1964 includes the following morphologically and biometrically very similar species parasitising freshwater fishes in Africa: C. citharini Khalil, 1964 (type species), C. gonzalezi Van Waerebeke, Chabaud, Bain et Georges, 1988, C. khalili Petter, Vassiliadès et Troncy, 1972 and C. petterae Khalil, 1974 (see Khalil 1964, 1974, Petter et al. 1972, Van Waerebeke et al. 1988, Koubková et al. 2010). Koubková et al. (2010) revised Cithariniella spp. based on the newly collected material, assigned to three previously known species, from six fish hosts in Senegal; they provided a key to species, reporting some new morphological and biometrical interspecific characters.

It has been revealed by SEM that there are distinct interspecific differences among Cithariniella spp. in the size of cephalic papillae (Koubková et al. 2010): while the width ratio of the cephalic papilla and the dorsal lip is ca $1: 2$ in C. khalili and C. gonzalezi (see Moravec 1994, Koubková et al. 2010, Mašová 2012), it is 1 : 3-4 in C. citharini and C. petterae (see Koubková et al. 2010). As can be seen in Fig. 8A,B, such ratio is $c a 1: 3$ in the present nematodes from $S$. intermedius, so they belong to the former group consisting of two species, both of which are parasites of Characiformes (whereas the type hosts of $C$. khalili and C. gonzalezi are Siluriformes); moreover, C. longicaudata sp. n. as well as $C$. citharini and $C$. petterae possess a single caudal papilla situated some distance posterior to the cloaca, whereas $C$. khalili and $C$. gonzalezi are reported to have a pair of such papillae (see Koubková et al. 2010).

The new species can be differentiated from $C$. citharini by the absence of the precloacal sucker-like organ and by the shorter spicule $(108 \mu \mathrm{m} v s$ 166-190 $\mu \mathrm{m})$ in male and by the length of entire oesophagus $(644-718 \mu \mathrm{m} v \mathrm{~s}$ 407-500 $\mu \mathrm{m})$ and the vulva-anus distance (490-694 $\mu \mathrm{m}$ vs $109-270 \mu \mathrm{m}$ ) in gravid female; moreover, C. citharini possesses narrow lateral alae in both sexes (Koubková et al. 2010), which are absent in C. longicaudata. It differs from $C$. petterae mainly in the shape of cephalic papillae (markedly transverse oval vs almost circular in apical view) and the length of the entire oesophagus in gravid female (644-718 $\mu \mathrm{m}$ vs 770-950 $\mu \mathrm{m})$.

Moravec (1974) reported C. citharini from Synodontis schall (Bloch et Schneider) in Egypt. Because he observed the usually single large caudal papilla located some distance posterior to the cloaca to be paired in some specimens, he considered $C$. khalili as probably identical with C. citharini. However, his (Moravec 1994) later examination of these specimens by SEM showed that their cephalic papillae are markedly wide, very different from those in C. citharini, but similar to those of $C$. khalili (see Koubková et al. 2010). According to Petter et al. (1972) and Koubková et al. (2010), C. khalili is characterised by the presence of two closely adjoining caudal papillae some distance posterior to the cloaca. However, since both a single large papilla or two closely adjoing papillae were reported for specimens from S. schall in Egypt by Moravec (1974 - see above), there are no other taxonomically important differences and the hosts are congeneric, the respective Egyptian specimens should be considered to belong to $C$. khalili. It is highly probable that, as the worm grows, the originally two separated caudal papillae are gradually fused together in larger specimens. Consequently, the nematodes reported by Moravec (1974, 1994), Fahmy et al. (1976), El-Naffar et al. (1983), Imam et al. (1991) and Al-Bassel (2003) as C. citharini from Synodontis spp. in Egypt belong to C. khalili.

Moreover, in our opinion, C. gonzalezi, originally described from Synodontis longirostris Boulenger in the Central African Republic, should be considered a junior synonym of $C$. khalili, because the differences between these two species reported by Van Waerebeke et al. (1988), i.e. the oesophagus/body length ratio and the presence of two separated (but close) caudal papillae are apparently within the intraspecific variability of $C$. khalili. In contrast, the specimens from Paradistichodus dimidiatus (Pellegrin) (Distichodontidae) in Senegal, reported as C. gonzalezi by Koubková et al. (2010) and characterised by digital genital papillae (all) and mutually conspicuously distant papillae of the pair situated some distance posterior to the cloaca, represent undoubtedly an undescribed species.

Based on the description provided by Koubková et al. (2010), we propose to establish a new species for their specimens from $P$. dimidiatus, for which the name C. koubkovae sp. n. is proposed (ZooBank number for species: urn:lsid:zoobank. org:act:FCB8DC00-4E52-45C9-8ADF-2CC205065150). This species mainly differs from congeners in possessing large cephalic papillae (width ratio of cephalic papilla and dorsal lip $1: 2$ ) and by the character of genital papillae as described above.

Type host: Paradistichodus dimidiatus (Pellegrin) (Distichodidae).

Site of infection: Intestine.

Type locality: Gambia River, Senegal.

Prevalence: $60 \%$.

Deposition of type specimens: Helminthological Collection 

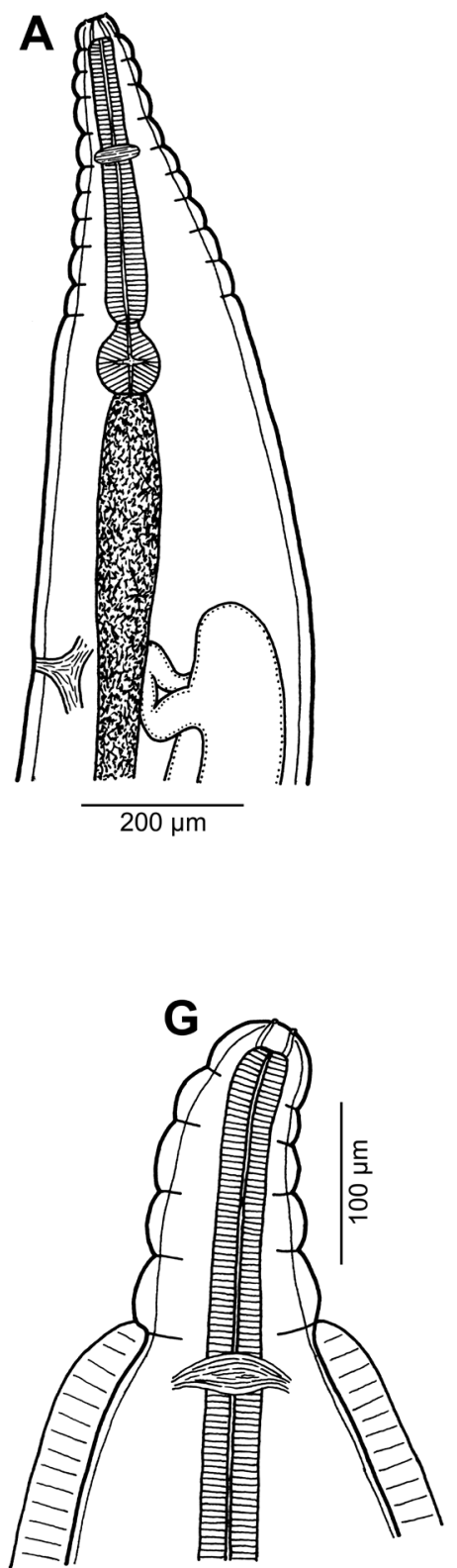

B

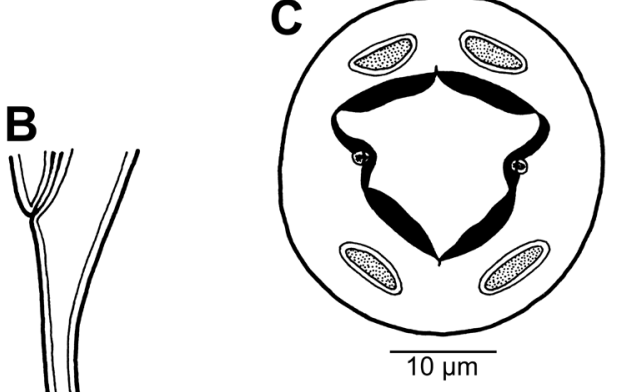

$\mathbf{F}$

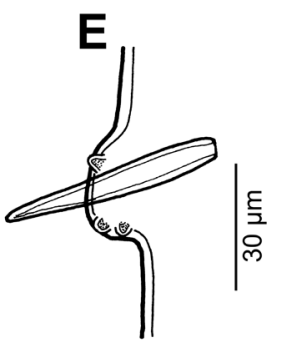

C

|| \begin{tabular}{||}
$\mid$ \\
$\frac{\xi}{2}$ \\
¿
\end{tabular}
D

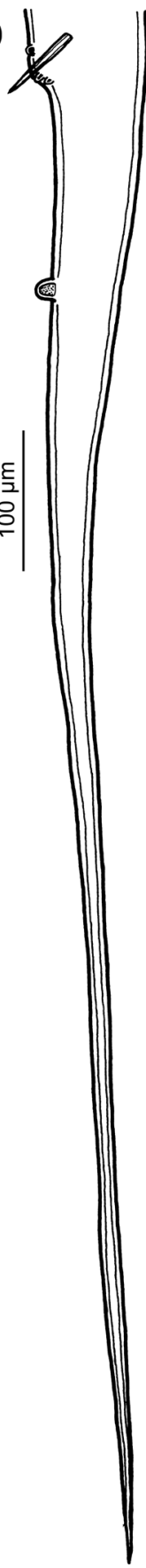

Fig. 9. Synodontisia annulata sp. n. from Schilbe intermedius Rüppel. A - anterior end of female, lateral view; $\mathbf{B}$ - tail of female, lateral view; $\mathbf{C}$ - cephalic end of female, apical view; $\mathbf{D}$ - tail of male, lateral view; $\mathbf{E}$ - region of cloaca, $\mathbf{F}$ - postanal papilla situated some distance posterior to cloaca, ventral view; $\mathbf{G}$ - cephalic end of female, dorsoventral view; $\mathbf{H}$ - egg.

of the Institute of Parasitology, Biology Centre of the Czech Academy of Sciences, České Budějovice (Cat. No. N-905).

Etymology: This species is named in honour of Božena Koubková, an outstanding Czech helminthologist.

Without providing morphometrical data, Dougnon et al. (2012) reported C. petterae, a parasite of Distichodidae, from Synodontis nigrita Valenciennes and S. schall (Mochokidae) in Benin. Since both these fish species are known as the hosts of $C$. khalili, it is highly probable that, in this case, $C$. khalili was misidentified for $C$. petterae.

Eyo et al. (2013) reported Oxyuris equi (Schrank, 1788) from $18 \%$ of Synodontis batensoda Rüppel examined from the Niger-Benue Rivers confluence, Nigeria. This is an evident species misidentification and the oxyuroid nematodes found probably belonged to Cithariniella khalili, which is known to parasitise $S$. batensoda in Senegal (Koubková et al. 2010).

Synodontisia annulata sp. n.

Figs. 9, 10

ZooBank number for species:

urn:Isid:zoobank.org:act:129E1068-F26F-4784-B531-1BEDCC00BA82

Description: Small, whitish nematodes; male markedly smaller than gravid females. Body fusiform; cuticle dis- 

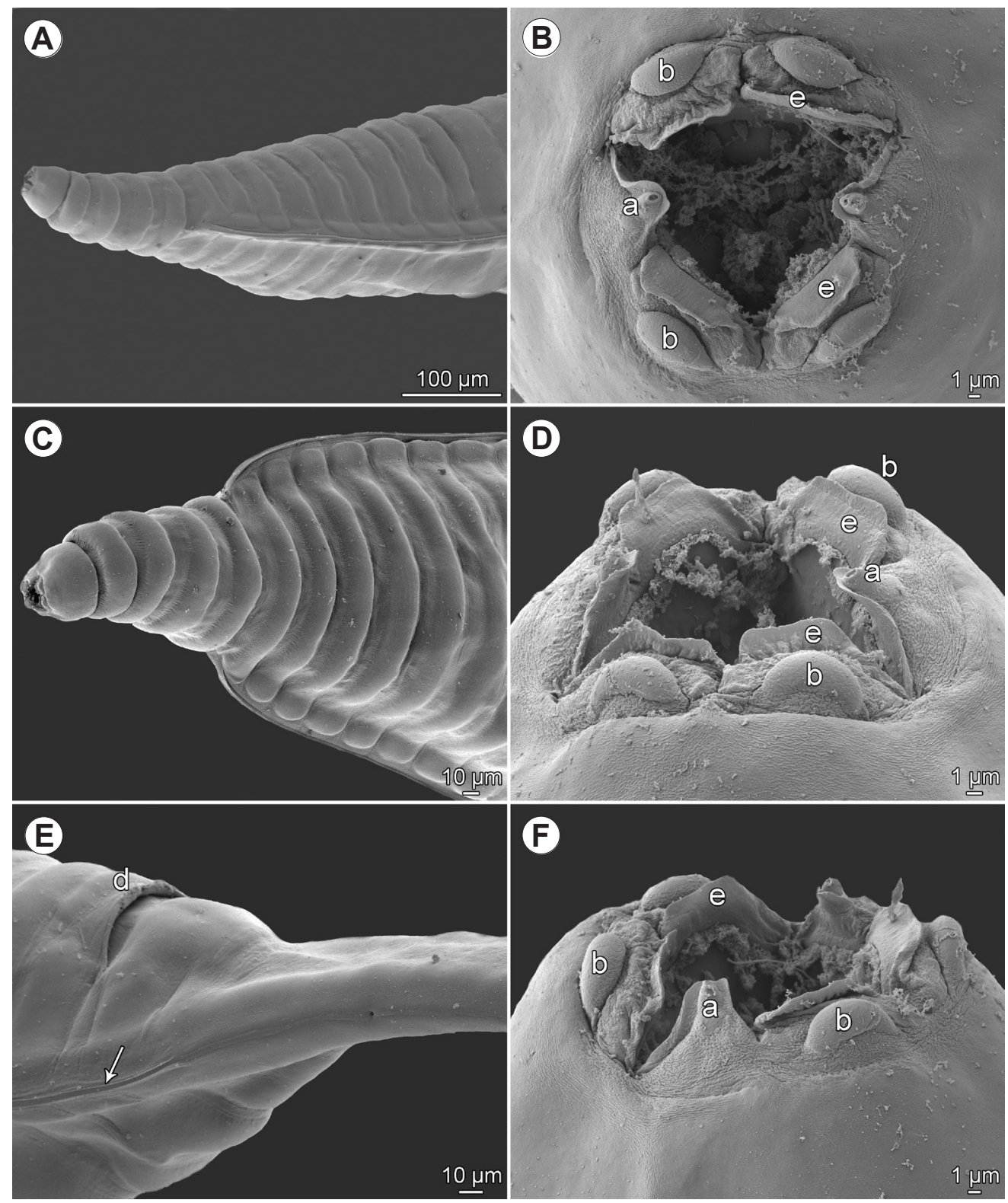

Fig. 10. Synodontisia annulata sp. n. female from Schilbe intermedius Rüppel, scanning electron micrographs. A - anterior end, lateral view; B - cephalic end, apical view; C - anterior end, ventral view; D - cephalic end, dorsal view; $\mathbf{E}$ - region of anus, lateral view (arrow indicates lateral ala); F - cephalic end, lateral view. Abbreviations: a - amphid; b - cephalic papilla; d - anus; e - mouth lamella.

tinctly transversely annulated (Figs. 9A,G, 10A,C). Narrow lateral alae arise anteriorly somewhat anterior to level of nerve ring and extend posteriorly slightly posterior to level of anus in females and to short distance posterior to median postanal papilla in male (Figs. 9G, 10A,C,E). Oral aperture surrounded by 6 small lip-like formations (2 dorsolateral, 2 ventrolateral and 1 lateral on each side), each of them provided with anteriorly protruding mouth lamella on inner side. Four large, oval submedian cephalic papillae and pair of small lateral amphids present (Figs. 9C, 10B,D,F). Buccal cavity spacious (Fig. 9A,G). Oesophagus formed by long, almost cylindrical corpus (without distinct pharyngeal portion), short isthmus and well-developed bulb; oesophagus opens into intestine through minute valve (Fig. 9A). Nerve ring situated at about mid-level of corpus; excretory pore at some distance posterior to oesophagus
(Fig. 9A). Tail of both sexes forms very long, slender caudal spike (Fig. 9B,D).

Male (1 specimen): Length of body including caudal spike $2.56 \mathrm{~mm}$, maximum width 245. Buccal cavity 9 long. Entire oesophagus 345 long; corpus 261 long, 27 wide; isthmus 12 long, 21 wide; bulb 63 long, 57 wide. Nerve ring and excretory pore 189 and 585 from anterior extremity, respectively. Genital cone truncate, bearing 1 pair of preanal papillae immediately anterior to cloaca and 2 pairs of postanal papillae, of which papillae of 2 nd postanal pair distinctly smaller and situated more ventrally; large, lobelike single median postanal papilla present 177 posterior to genital cone (at $1.1 \mathrm{~mm}$ from tail tip) (Fig. 9D-F). Spicule simple, well sclerotised, 66 long, with sharply pointed distal tip (Fig. 9D,E). Tail $1.20 \mathrm{~mm}$ long (47\% of body length) (Fig. 9D). 

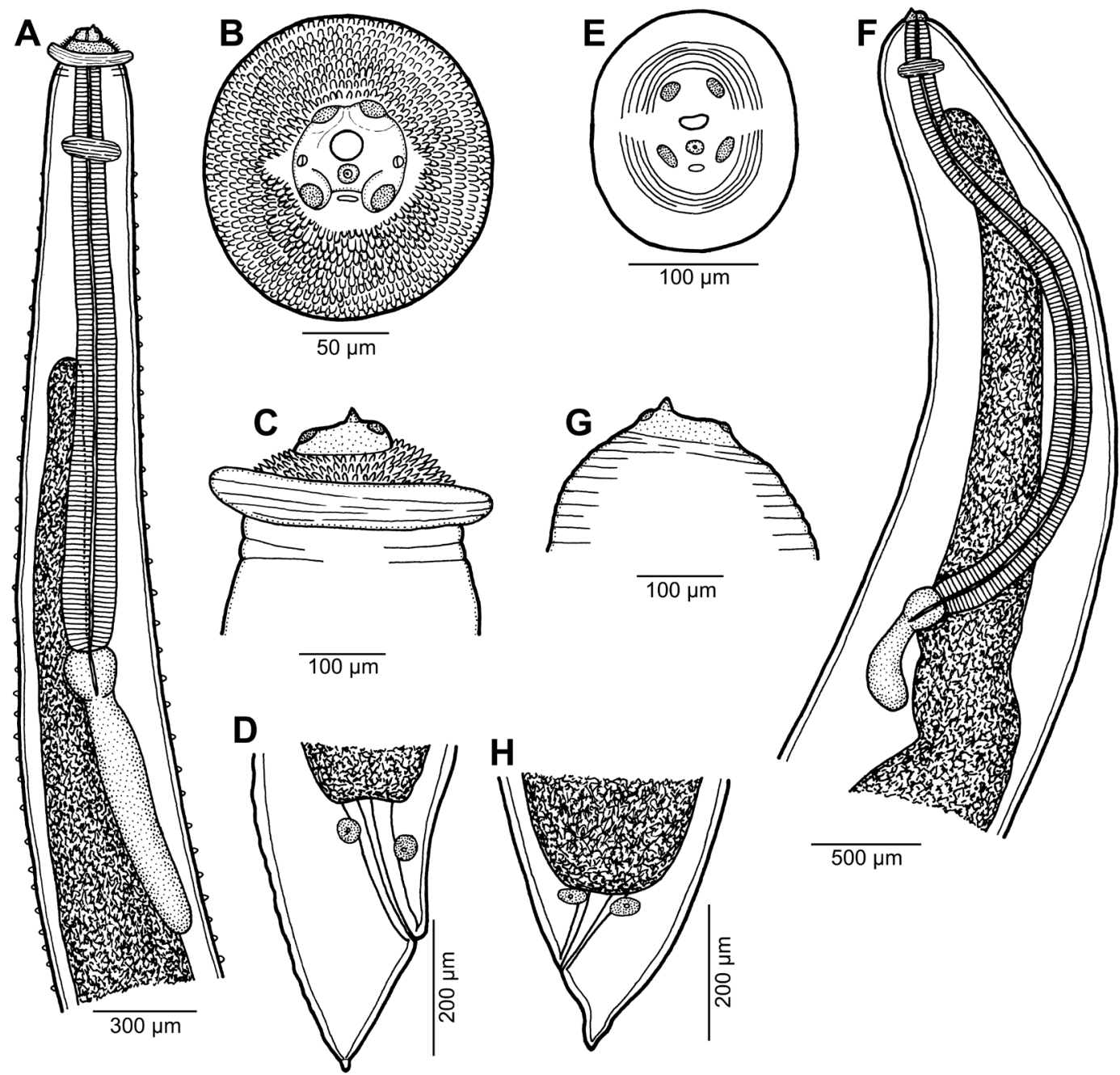

$500 \mu \mathrm{m}$

Fig. 11. A-D - Galeiceps sp. third-stage larva from Hydrocynus vittatus Castelnau (A - anterior end, lateral view; $\mathbf{B}, \mathbf{C}-$ cephalic end, apical and lateral views, respectively; D - tail, lateral view); $\mathbf{E}-\mathbf{H}$ - Contracaecum sp. third-stage larva from Hydrocynus vittatus ( $\mathbf{E}$ - cephalic end, apical view; $\mathbf{F}$ - anterior end, lateral view; $\mathbf{G}$ - cephalic end, lateral view; $\mathbf{H}$ - tail, lateral view).
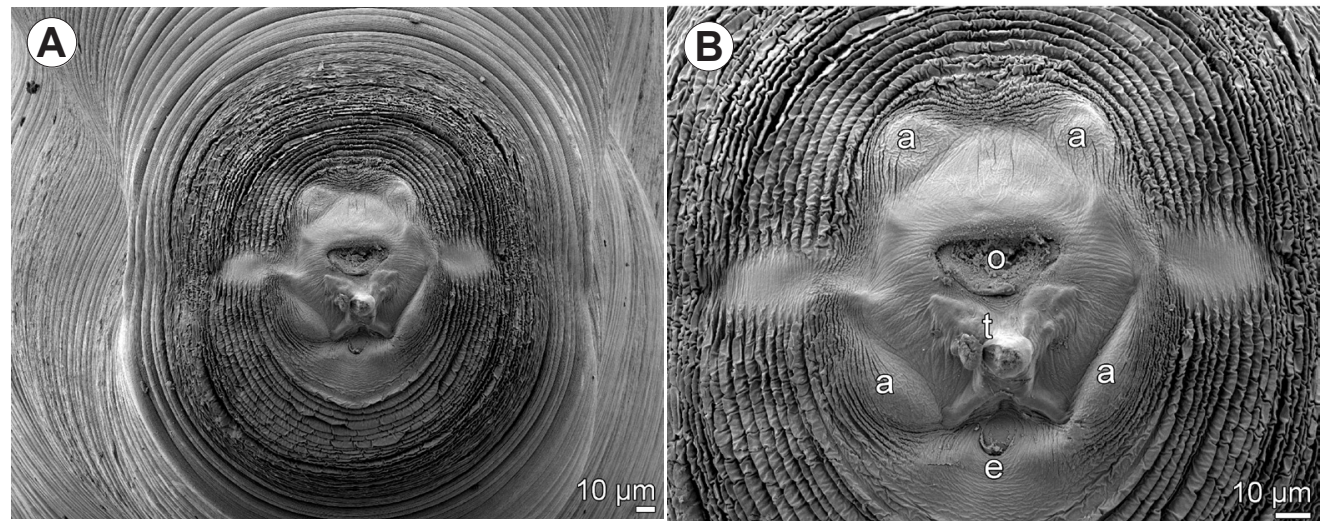

Fig. 12. Contracaecum sp. third-stage larva from Hydrocynus vittatus Castelnau, scanning electron micrographs of cephalic end. A - apical view; B - same, higher magnification. Abbreviations: a - cephalic papilla; $\mathrm{e}$ - excretory pore; $\mathrm{o}$ - oral aperture; $\mathrm{t}$ - larval tooth.

Female (2 gravid specimens; body measurements of 1 nongravid specimen in parentheses): Body distinctly fusiform, broadest at level of vulva; length including caudal spike 4.88-5.33 (2.83) mm, maximum width 476-517 (245). Annulation of body conspicuous; length of annula- tions at anterior end of body 15-45. Lateral alae arise anteriorly on 6th annule, at 123-204 from anterior extremity; maximum width of alae 24-36 (Figs. 9G, 10A,C). Buccal cavity 18 long, 21 wide. Entire oesophagus 453-513; corpus 354-408 long, 45-48 wide; isthmus 9 long, 30 wide; 

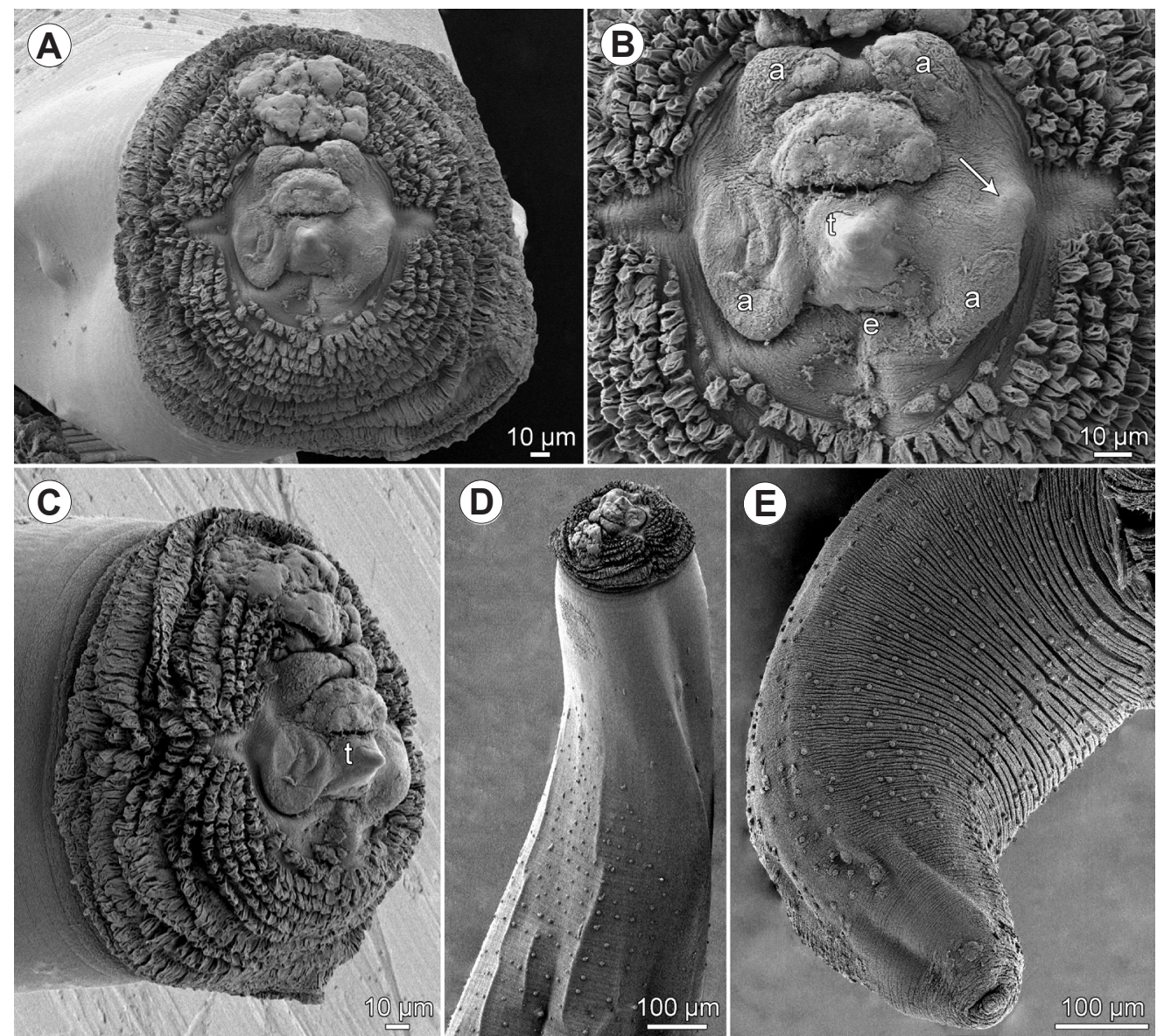

Fig. 13. Galeiceps sp. third-stage larva from Hydrocynus vittatus Castelnau, scanning electron micrographs. A - cephalic end, apical view; B - same, higher magnification (arrow indicates amphid); C - cephalic end, lateral view; $\mathbf{D}$ - anterior end, ventrolateral view; E - posterior end, sublateral view. Abbreviations: a - cephalic papilla; e - excretory pore; $\mathrm{t}$ - larval tooth.

bulb 90-96 long, 99-108 wide. Nerve ring and excretory pore 190-258 and 870 from anterior extremity, respectively. Location of vulva not determined due to damage of specimens. Mature eggs elongate-oval, 138-168 × 60-69, thin-walled, with still uncleaved content (Fig. 9H). Tail 2.00-2.12 mm long (37-43\% of body length) (Fig. 9B). Pair of small phasmids situated laterally short distance posterior to anus (Fig. 10E).

Type host: Silver catfish, Schilbe intermedius Rüppel (Schilbeidae); body length $228 \mathrm{~mm}$.

Site of infection: Intestine.

Type locality: Okavango River (Shakawe mainstream $18^{\circ} 26^{\prime} 05^{\prime \prime S} ; 21^{\circ} 54^{\prime} 23^{\prime \prime E}$ ), Botswana (collected 19 August 2001).

Prevalence: $1.5 \%$ ( 1 fish infected/66 fish examined).

Deposition of type specimens: Helminthological Collection of the Institute of Parasitology, Biology Centre of the Czech Academy of Sciences, České Budějovice (Cat. No. N-1085).

Etymology: The specific name annulata relates to the characteristic feature of these nematodes, i.e. a conspicuously annulated body.

Remarks. To date, only two species of Synodontisia Petter, Vassiliadès et Troncy, 1972 have been described: S. thelastomoides Petter, Vassiliadès et Troncy, 1972 (type species) and $S$. okavangoensis Moravec et Van As, 2004, both of them from squeaker fishes Synodontis spp. in Africa (Petter et al. 1972, Moravec and Van As 2004). The new species distinctly differs from S. okavangoensis in the shape of cephalic papillae (broad, oval vs narrow, crescent-shaped), much longer body of the male $(2.56 \mathrm{~mm}$ vs $1.21 \mathrm{~mm})$ but, in contrast, a shorter spicule $(66 \mu \mathrm{m} v \mathrm{~s}$ $87 \mu \mathrm{m})$, the relative length of the male oesophagus representing $2.6 \%$ ( $v s 7.2 \%$ ) of the body length, and in considerably larger gravid females (body length 4.88-5.33 $\mathrm{mm} v \mathrm{~s}$ 2.72-3.54 mm).

The morphology of $S$. annulata sp. n. is rather similar to that of S. thelastomoides, but the body of the former species is conspicuously larger (body length of male and gravid female $2.56 \mu \mathrm{m}$ and $4.88-5.33 \mu \mathrm{m} v s 1.15 \mu \mathrm{m}$ and $2.56 \mu \mathrm{m}$, respectively) and both species differ in the relative length of the entire oesophagus, representing $2.6 \%$ in male and $8-11 \%$ in gravid female of the body length of $S$. annulata, respectively ( $v s 5 \%$ in male and $14 \%$ in gravid female of $S$. thelastomoides). However, it is necessary to remark that S. thelastomoides has not yet been studied by SEM, which may reveal additional interspecific differences. While the hosts of $S$. okavangoensis and $S$. thelastomoides belong to the family Mochokidae, that of $S$. annulata sp. n. is a representative of the Schilbeidae. 

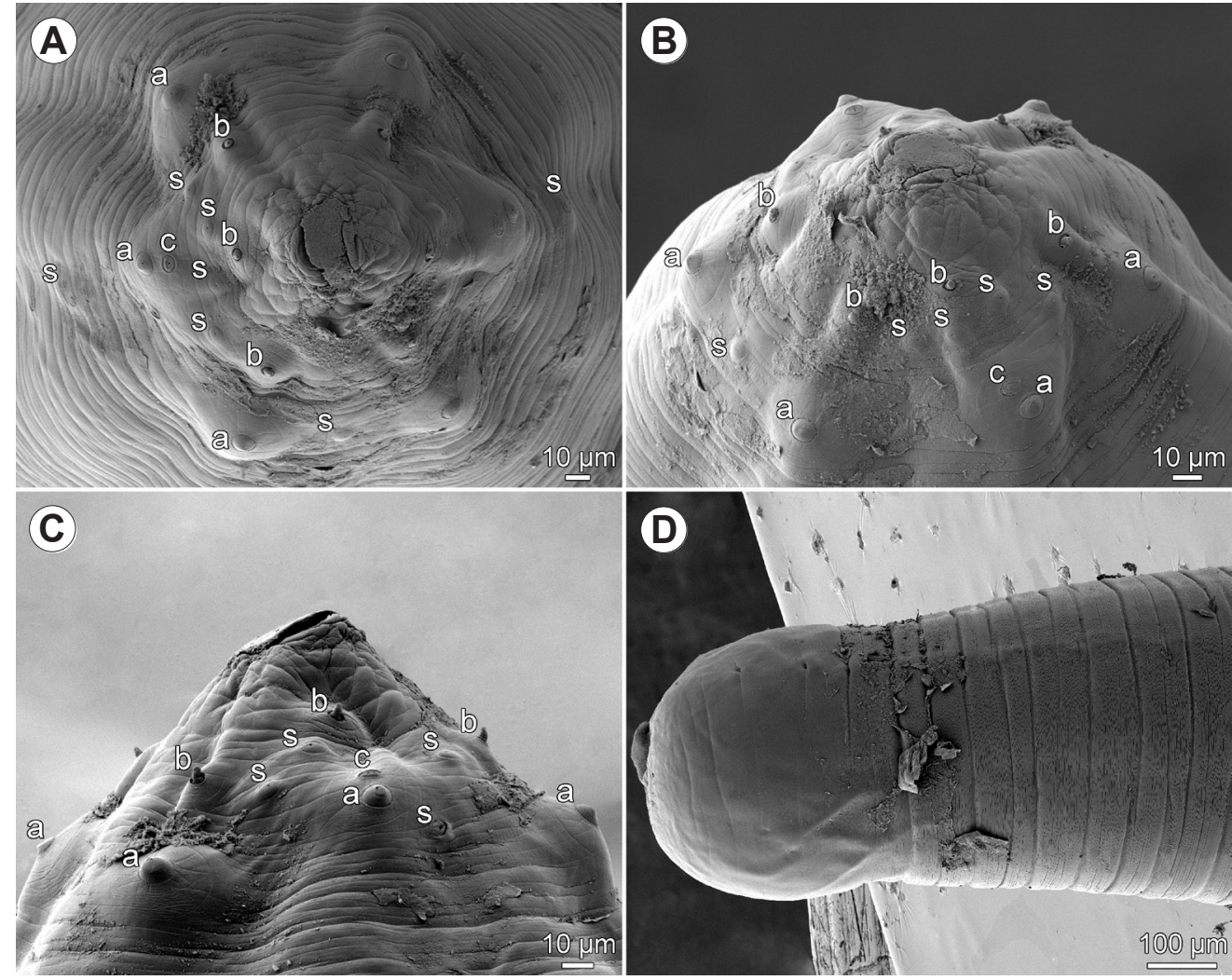

Fig. 14. Eustrongylides sp. male fourth-stage larva from Hydrocynus vittatus Castelnau, scanning electron micrographs. A-C - cephalic end, apical, sublateral and lateral views, respectively; D - posterior end, lateral view. Abbreviations: a - cephalic papilla of external circle; $\mathrm{b}$ - cephalic papilla of internal circle; $\mathrm{c}$ - amphid; $\mathrm{s}$ - somatic papilla.

Ascaridoidea Railliet et Henry, 1915

Anisakidae Railliet et Henry, 1912

Contracaecum sp. third-stage larvae

Figs. $11 \mathrm{E}-\mathrm{H}, 12$

Description (2 specimens from Hydrocynus vittatus Castelnau): Body whitish, 19.3-21.5 mm long and $1.24-1.33 \mathrm{~mm}$ wide. Transverse striations of cuticle more distinct on body ends (Figs. 11E,G, 12A,B). Cephalic end rounded, bearing small ventral cuticular tooth and 4 cephalic submedian cephalic papillae surrounding small transverse oval oral aperture; anlagen of lips weakly developed (Figs. 11E,G, 12A,B). Excretory pore situated below ventral cephalic tooth. Somewhat elevated region of cephalic papillae surrounded by several low, circular cuticular lamellae interrupted by narrow smooth lateral fields (Figs. 11E, 12A,B). Oesophagus narrow, 2.35-2.75 mm long, 122-163 wide. Ventriculus small, rounded, size 109-190 × 150-190; posterior ventricular appendix short, 394-490 long and 122-136 wide. Nerve ring 272-340 from anterior extremity. Intestine brownish. Intestinal caecum very long, extending anteriorly almost to nerve ring; its length 1.67-2.07 mm, maximum width 326 (Fig. 11F). Length ratio of caecum and ventricular appendix 1 : $0.2-0.3$. Genital primordium indistinct. Rectum short hyaline tube; 3 small unicellular rectal glands present. Tail conical, 136-218 long (Fig. 11H).
Hosts: Tiger fish, Hydrocynus vittatus Castelnau (Alestidae, Characiformes), body length $501 \mathrm{~mm}$, blotched catfish, Clarias stappersi Boulenger (Clariidae, Siluriformes), body length 220 $\mathrm{mm}$, rainbow happy, Sargochromis carlottae (Boulenger), body length $199 \mathrm{~mm}$, thinface cichlid, Serranochromis angusticeps (Boulenger), body length $260 \mathrm{~mm}$, purpleface largemouth, Serranochromis macrocephalus (Boulenger), body length $268 \mathrm{~mm}$, and southern mouthbrooder, Pseudocrenilabrus philander (Weber), body length $50 \mathrm{~mm}$ (all Cichlidae, Perciformes).

Site of infection: Viscera.

Locality: Okavango River (Mokoro lagoon 18²5'19.7"S; $21^{\circ} 56^{\prime} 19.9^{\prime \prime E}$ ), Botswana (collected 20 August 2001).

Prevalence: $H$. vittatus: 9\% (1 fish infected/11 fish examined); C. stappersi: $1 / 6 ;$ S. carlottae: $1 / 5 ;$ S. angusticeps: $7 \%(1 / 15)$; S. macrocephalus: $9 \%(1 / 11) ;$. philander: $1 / 9$.

Deposition of voucher specimens: Helminthological Collection of the Institute of Parasitology, Biology Centre of the Czech Academy of Sciences, České Budějovice (Cat. No. N-468).

Remarks. Recorded third-stage larvae of Contracaecum Railliet et Henry, 1912 are characterised by the presence of a conspicuously long intestinal caecum reaching nearly to the nerve ring and a relatively short ventricular appendix. Such larvae were designated as Type 2 by Moravec et al. (1993) and, in fact, they may belong to the morphological group of several species parasitising mainly fish-eating birds as adults. The species identification of Contracaecum larvae from fishes, which serve as paratenic hosts (Moravec 2009) based on morphometrical features is practically impossible. 
In Africa, morphologically similar larvae were reported, e.g. by Barson and Avenant-Oldewage (2006) from Clarias gariepinus (Burchell) in South Africa.

Larvae of Contracaecum have frequently been reported as parasites of many (almost 60) species of freshwater fishes in Africa, belonging to different families and orders, for example in Democratic Republic of the Congo, Egypt, Kenya, Mali, Mozambique, Nigeria, Senegal, South Africa, Sudan, Tanzania, Uganda and Zimbabwe (e.g. Baylis 1930, 1940, Campana-Rouget 1961, Vassiliadès 1975, Mashego 1989, Boomker 1994, Otachi et al. 2014). Except for $H$. vittatus previously reported as the host of Contracaecum larvae in Zimbabwe and South Africa by Khalil (1974) and Boomker (1994), all other fish hosts of these parasites mentioned in this paper represent new host records; Contracaecum larvae are reported from fishes in Botswana for the first time.

\section{Galeiceps sp. third-stage larvae}

Figs. 11 A-D, 13

Description (5 specimens from $H$. vittatus; measurements of 1 specimen from $C$. gariepinus in parentheses): Body whitish, 20.5-27.9 mm (24.56 mm) long and 680 898 (666) wide, anterior end with distinct cuticular collar 299-381 (340) wide; surface of space between collar and base of anlagen of lips covered by numerous small, protruding cuticular plates arranged in rows; cuticle posterior to cephalic collar finely transversally striated (Figs. 11A-C, 13A-D). Body covered by many small cuticular bosses; embossment starts short distance posterior to cephalic collar and extends posteriorly to region of anus (Figs. 11A, 13D,E). Cephalic extremity smooth, somewhat elevated, provided with 4 submedian cephalic papillae surrounding oval oral aperture, pair of small lateral amphids and small ventral cuticular tooth. Excretory pore situated below ventral cephalic tooth (Figs. 11B,C, 13A-D). Oesophagus narrow, 1.75-2.53 (2.11) mm long, 136-218 (163) wide. Ventriculus small, rounded, 150-204 × 136-231 $(122 \times 150)$ in size; posterior ventricular appendix 748-1,061 (925) long and 136-163 (136) wide. Nerve ring 272-490 (408) from anterior extremity. Intestine brown. Intestinal caecum extends anteriorly to about middle of oesophagus length (Fig. 11A), 1.18-2.57 (1.17) mm long, maximum width 136-299 (177). Length ratio of caecum and ventricular appendix $1: 0.5-1.1$ (1:0.8). Genital primordium indistinct. Rectum short hyaline tube; 3 small unicellular rectal glands present. Tail conical, 109-245 (163) long, with a small digital mucron at tip (Figs. 11D, 13E).

Hosts: Tiger fish, Hydrocynus vittatus Castelnau (Alestidae, Characiformes), body length $501 \mathrm{~mm}$, and North African catfish, Clarias gariepinus (Burchell) (Clariidae, Siluriformes), body length $726 \mathrm{~mm}$.

Site of infection: Viscera.

Locality: Okavango River (Mokoro lagoon 18²5'19.7"S; $21^{\circ} 56^{\prime} 19.9^{\prime \prime E}$ ), Botswana (collected 20 August 2001).

Prevalence: $H$. vittatus: 1 fish infected $/ 8$ fish examined; C. gariepinus: $2 \%(1 / 45)$.

Deposition of voucher specimens: Helminthological Collection of the Institute of Parasitology, Biology Centre of the
Czech Academy of Sciences, České Budějovice (Cat. No. N-1087).

Remarks. By the general morphology, especially the structure of the cephalic end, these larvae belong to the genus Galeiceps Railliet, 1916 (syn. Cloeoascaris Baylis, 1923). Adults of three species of this genus were described from semiaquatic mammals in Africa (Chabaud et al. 1967): the type species, G. cucullus (Linstow, 1899), originally described by Linstow (1899) as Ancyracanthus cucullus Linstow, 1899 from the giant otter shrew Potamogale velox (Du Chaillu) (Tenrecidae, Afrosoricida) in Cameroon and later redescribed from the same host species by Chabaud et al. (1967) in Gabon; G. spinicollis (Baylis, 1923) described by Baylis (1923b) as Cloeoascaris spinicollis Baylis, 1923 from 'Lutra sp.' [probably the spotted-necked otter Hydrictis maculicollis (Lichtenstein)] (Mustelidae, Carnivora), the marsh mongoose Atilax paludinosus Cuvier and Atilax sp. (both Herpestidae, Carnivora); and G. simiae (Mozgovoy, 1951), established for specimens originally identified by Schuurmans Stekhoven (1937) as Cloeoascaris spinicollis allegedly from the stomach of the monkey Cercopithecus leucampyx kandti Matschiein in the present Democratic Republic of the Congo. However, Sprent (1982) corrected an error in the host record of G. spinicollis to Lutra (= Hydrictis) maculicollis kivuana (Pohle) and considered G. simiae to be a junior synonym of $G$. spinicollis.

Considering the geographical distribution of the definitive hosts of G. cucullus and G. spinicollis, the larvae of the present material from Botswana probably belong to the latter species, the main definitive host of which, the spotted-necked otter H. maculicollis, occurs in the Okavango River in Botswana. The life cycle of any Galeiceps spp. remain unknown but, judging from the morphological similarity of these nematodes to Contracaecum spp., the way of their development and transmission of larvae to the definitive host are probably much the same as in Contracaecum spp. Consequently, it can be assumed that the fish-eating mammalian definitive hosts acquire the Galeiceps infection while feeding on fishes harbouring infective third-stage larvae of these nematodes.

To date, larvae of any Galeiceps spp. have been neither described nor recorded from fishes, so the present finding represents the first report in this respect. It is worth mentioning that the presence of many cuticular bosses on the body of Galeiceps sp. third-stage larvae is quite exceptional among all ascaridoid nematodes and has been observed neither in adults of Galeiceps spp. nor in any other adult or larval ascaridoid nematodes.

Dioctophymatoidea Castellani et Chalmers, 1910

Dioctophymatidae Castellani et Chalmers, 1910

Eustrongylides sp. fourth-stage larvae

Figs. 3 E-G, 14

Description (1 specimen from Hydrocynus vittatus): Body of male larva filiform, yellowish, $98.6 \mathrm{~mm}$ long and 
$1.09 \mathrm{~mm}$ in maximum width. Cephalic extremity conical, posterior end of body rounded (Figs. 3E,F, 14C,D). Cuticle distinctly transversely striated (Fig. 14A-D). Oral aperture small, oval, surrounded by 12 cephalic papillae arranged in 2 circles; each circle formed by 2 lateral, 2 subdorsal and 2 subventral papillae; papillae of inner circle smaller, with spike-like apices. Pair of small lateral amphids resembling somatic papillae located just anterior to lateral cephalic papillae of outer circle. Four small sublateral field somatic papillae present between inner and outer circle of cephalic papillae (Figs. 3E,G, 14 A-C). Buccal cavity 177 long; length of oesophagus $27.0 \mathrm{~mm}$, maximum width 816 (Fig. $3 E)$. Nerve ring encircling oesophagus 367 from anterior extremity. Posterior extremity blunt, with slightly elevated region of anus (Figs. 3F, 14D); developing copulatory bursa, 462 long and 476 wide, already present, but still inside larval cuticle (Fig. 3F).

Hosts: Tiger fish, Hydrocynus vittatus Castelnau (Alestidae, Characiformes), body length $501 \mathrm{~mm}$, and purpleface largemouth, Serranochromis macrocephalus (Boulenger) (Cichlidae, Perciformes), body length $268 \mathrm{~mm}$.

Site of infection: Abdominal cavity.

Locality: Okavango River Delta (Mokoro lagoon 18²5'19.7"S; $\left.21^{\circ} 56^{\prime} 19.9^{\prime \prime E}\right)$, Botswana (collected 20 August 2001).

Prevalence: H. vittatus: 1 fish infected/8 fish examined; S. macrocephalus: $9 \%(1 / 11)$.

Deposition of voucher specimens: Helminthological Collection of the Institute of Parasitology, Biology Centre of the Czech Academy of Sciences, České Budějovice (Cat. No. N-76).

Remarks. Third- and fourth-stage larvae of Eustrongylides Jägerskiöld, 1909 from fishes and some other aquatic vertebrates are unidentifiable to species by morphological and biometrical features and the only reliable way to determine the species is to obtain adult nematodes from experimental infections of definitive hosts (birds) or by the use of molecular methods (Measures 1988a, Moravec 2013). Adults of this genus are parasites of the proventriculus of fish-eating birds. Aquatic oligochaetes serve as the first intermediate hosts, whereas fishes act as the second intermediate hosts or the paratenic hosts; paratenic hosts may be also some amphibians and aquatic reptiles (e.g. Karmanova 1968, Measures 1988b, Anderson 2000). The ability of Eustrongylides infective larvae to re-establish in a new paratenic host was experimentally demonstrated by Von Brand (1944). Eustrongylides fourth-stage larvae are occasionally found as the parasites of humans after being ingested along with raw fish; in such cases, the larvae usually penetrate through the wall of the caecum into the peritoneal cavity and can be removed only during surgery (Eberhard et al. 1989).

To date, the only nominal Eustrongylides species reported from Africa is E. africanus Jägerskiöld, 1909, which was originally inadequately described by Jägerskiöld (1909) solely from females found in some aquatic birds in the Sudan. Later, Paperna (1974) recovered many adult male specimens identified as E. africanus from the stomach of naturally and experimentally infected cormorants Phalacrocorax (= Microcarbus) africanus (Gmelin) in Lake Victoria, Uganda, but, unfortunately, he did not redescribe this species. He also considered the Eustrongylides larvae commonly found in many fish species from East African lakes to belong to E. africanus. However, the validity of $E$. africanus was questioned by the revisionary study of Measures (1988a), who designated E. africanus as a species inquirenda. Consequently, the species belonging of the Eustrongylides larvae, which are frequently recorded from freshwater fishes in Africa, remains unclear and it may well be that these nematodes represent more than one species.

Eustrongylides larvae have already been reported from a variety of fish species in Africa, mainly those belonging to the family Cichlidae, for example in Tanzania, Uganda, the Democratic Republic of the Congo, Nigeria and Senegal (e.g. Baylis 1928, 1940, Campana-Rouget 1961, Khalil and Thurston 1973, Paperna 1974, Vassiliadès 1975, Sikoki et al. 2013). The present findings of Eustrongylides sp. larvae in $H$. vittatus and $S$. macrocephalus represent new host and geographical records.

Acknowledgements. We thank the National Research Foundation, South Africa, for financial support. The authors' thanks are also due to the staff of the Laboratory of Electron Microscopy, Institute of Parasitology, Biology Centre of the CAS, České Budějovice, for their technical assistance, and to Blanka Škoríková of the same Institute for help with illustrations. This study was partly supported by the Czech Science Foundation (Grant. No. P505/12G112) and by institutional support (RVO: 60077344, Institute of Parasitology, BC AS CR).

\section{REFERENCES}

Abdel-Ghaffar F., Bashtar A.-R., Abdel-Gaber R., Morsy K., Mehlhorn H., Al Quraishy S., Mohammed S. 2014: Cucullanus egyptae sp. nov. (Nematoda, Cucullanidae) infecting the European eel Anguilla anguilla in Egypt. Morphological and molecular phylogenetic studies. Parasitol. Res. 113: 3457-3465.

Al-Bassel D.A.H.M. 2003: A general survey of the helminth parasites of fish from inland waters in the Fayoum Governorate, Egypt. Parasitol. Res. 90: 135-139.

Aмıм O.M. 1978: Intestinal helminths of some Nile fishes near Cairo, Egypt with redescriptions of Camallanus kirandensis Baylis, 1928 (Nematoda) and Bothriocephalus aegyptiacus Rysavy \& Moravec, 1975 (Cestoda). J. Parasitol. 64: 993-1101.
Anderson R.C. 2000: Nematode Parasites of Vertebrates. Their Development and Transmission. Second Edition. CABI Publishing, Wallingford and New York, 650 pp.

Anderson R.C., Chabaud A.G., Willmott S. (Eds.) 2009: Keys to the Nematode Parasites of Vertebrates. Archival Volume. CAB International, Wallingford, $463 \mathrm{pp}$.

BAKER M.R. 1982: Systematic relationships of the Atractidae and Cosmocercidae (Nematoda: Cosmocercoidea): two new atractids parasitic in amphibians and fish. Can. J. Zool. 60: 2395-2402.

Barson M., Avenant-Oldewage A. 2006: Nematode parasites of Clarias gariepinus (Burchell, 1822) from the Rietvlei Dam, South Africa. Onderstepoort J. Vet. Res.73: 87-94. 
BAYLIS H.A. 1923a: Some nematodes of the genus Cucullanus from fishes of the Nile. Ann. Mag. Nat. Hist., Ser. 9, 12: 233-236.

BAYlis H.A. 1923b: A new ascarid from an otter. Ann. Mag. Nat. Hist., Ser. 9, 2: 459-463.

BAYLIS H.A. 1928: Some parasitic worms, mainly from fishes, from Lake Tanganyika. Ann. Mag. Nat. Hist., Ser. 10, 4: 372-381.

Baylis H.A. 1930: Mission Saharienne Augiéras-Draper, 19271928. Parasitic nematodes. Bull. Mus. Nat. Hist. Nat, Paris, $2^{\circ}$ sér., 2: 117-130.

BAYLIS H.A. 1940: On a further collection of parasitic worms from the Belgian Congo. Ann. Mag. Nat. Hist., Ser. 11, 29: 401-417.

Boomker J. 1994: Parasites of South African freshwater fish. VII. Nematodes of some scaled fishes from the Hartbeespoort Dam, Transvaal. Onderstepoort J. Vet. Res. 61: 197-199.

Cabañas-Carranza G., Caspeta-Mandujano J.M. 2007: A new cucullanid species (Nematoda) from the freshwater fish Vieja intermedia (Günther, 1862) (Cichlidae) in Mexico. J. Parasitol. 93: 646-649.

Campana-Rouget Y. 1961: Nématodes de poissons. Rés. Sci. Explor. Hydrobiol. Lacs Kivu, Édouard et Albert (1952-1954), Bruxelles, 3: 1-61.

Caspeta-Mandujano J.M., Salgado-Maldonado G., MarTíNeZ-Ramírez E. 2010: A new cucullanid species (Nematoda) from the freshwater fish Thorichthys helleri (Cichlidae) in Mexico. Helminthologia 47: 33-37.

Černotíková E., Horák A., Moravec F. 2011: Phylogenetic relationships of some spirurine nematodes (Nematoda: Chromadorea: Rhabditida: Spirurina) parasitic in fishes inferred from SSU rRNA gene sequences. Folia Parasitol. 58: 135-148.

Chabaud A.-G., Bain O., Tcheprakoff R. 1967: Redescription de Galeiceps cucullus (Linstow 1899) et remarques sur l'osmorégulation des Nématodes Anisakides. Ann. Parasitol. Hum. Comp. 42: 321-326.

Dougnon J., Montchowui E., Daga F.D., Houessionon J., LALÉYÉ P., SAKiti N. 2012: Cutaneous and gastrointestinal helminth parasites of the fish Synodontis schall and Synodontis nigrita (Siluriformes: Mochokidae) from the lower Ouémé Valley in South Benin. Res. J. Biol. Sci. 7: 320-326.

Eberhard M.L., Hurwitz H., Sun A.M., Coletta D. 1989: Intestinal perforation caused by larval Eustrongylides (Nematoda: Dioctophymatoidae) in New Jersey. Am. J. Trop. Med. Hyg. 40: $648-650$.

El-Naffar M.K., SaOud M.F., Hassan I.M. 1983: A general survey of helminth parasites of some fishes of Lake Nasser at Aswan, A. R. Egypt. Assiut Vet. Med. J. 11: 141-183.

Eyo J.E., Iyaji F.O., Obiekezie A.I. 2013: Parasitic infestation of Synodontis batensoda (Rüppell, 1832, Siluriformes, Mockohidae [sic]) at Rivers Niger-Benue confluence, Nigeria. Afr. J. Biotechnol. 12: 3029-3039.

Fahmy M.A.M., Mandour A.M., El-Naffar M.K. 1976: On some nematodes parasites from the freshwater fishes in Assiut Province, Egypt. Veter. Med. J. 24: 263-276.

Froese R., Pauly D. (Eds.) 2015: FishBase. World Wide Web electronic publication, www.fishbase.org, version 02/2015.

Imam E.A., El-Askalany M.A., Rashad S.M. 1991: The helminth parasites of Synodontis schall and Bagrus bayad from Beni-Suef water resources. Assiut Vet. Med. J. 24: 137-152.

JÄGERSKIÖLD L.A. 1909: Zur Kenntnis der Nematoden-Gattungen Eustrongylides und Hystrichis. Nova Acta Regiae Soc. Sci. Upsaliensis, Ser. 4, 2: 1-48.

Karmanova E.M. 1968: [Dioctophymidea of Animals and Man and the Diseases Caused by Them.] Osnovy Nematodologii 20.Nauka, Moscow, 262 pp. (In Russian.)

Khalil L.F. 1964: Cithariniella citharini gen. et sp. nov. (Nematoda): an oxyurid from a freshwater fish, Citharinus citharus in the Sudan. J. Helminthol. 38: 41-46.

KHaliL L.F. 1969: Studies on the helminth parasites of freshwater fishes of the Sudan. J. Zool., Lond., 158: 143-170.
KHALIL L.F. 1974: Some nematodes from the freshwater fishes of Rhodesia with the description of a new species Cithariniella petterae n. sp. Ann. Parasitol. Hum. Comp. 48: 811-818.

Khalil L.F., Polling L. 1997: Check List of the Helminth Parasites of African Freshwater Fishes. Second Edition. University of the North, Pietersburg, $185 \mathrm{pp}$

Khalil L.F., Thurston J.P. 1973: Studies on the helminth parasites of freshwater fishes of Uganda including the descriptions of two new species of digeneans. Rev. Zool. Bot. Afr. 87: 209-248.

Koubková B., Baruš V., Hodová I. 2010: Nematodes of Cithariniella (Pharyngodonidae) from freshwater fishes in Senegal, with a key to species. Helminthologia 47: 105-114.

Koubková B., Baruš V., Hodová I., Šımková A. 2008: Morphometric and molecular characteristics of Labeonema synodontisi n. comb. (Nematoda: Atractidae) from the West African fishes. Parasitol. Res. 102: 1013-1020.

vON Linstow O. 1899: Nematoden aus der Berliner zoologischen Sammlung. Mitt. Zool. Mus., Berlin 1: 3-28.

MasheGo S.N. 1989: Nematode parasites of Barbus spp. in Lebowa and Venda, South Africa. South Afr. J. Wildl. Res. 19: 35-37.

MAšoví Š. 2012: Structure of the cephalic end and eggs of female Cithariniella khalili Petter, Vassiliadès et Troncy, 1972 (Nematoda: Pharyngodonidae), a parasite of African fishes. Helminthologia 49: 115-118.

Measures L. 1988a: Revision of the genus Eustrongylides Jägerskiöld, 1909 (Nematoda: Dioctophymatoidea) of piscivorous birds. Can. J. Zool. 66: 885-895.

Measures L. 1988b: The development of Eustrongylides tubifex (Nematoda: Dioctophymatoidea) in oligochaetes. J. Parasitol. 74: 294-304.

Morand S., Rigby M.C. 1998: Cucullanin nematodes from coral reef fishes of French Polynesia, with a description of Cucullanus faliexae n. sp. (Nematoda: Chitwoodchabaudiidae). J. Parasitol. 84: 1213-1217.

Moravec F. 1974: On some nematodes from Egyptian freshwater fishes. Acta Soc. Zool. Bohemoslov. 38: 32-51.

Moravec F. 1994: Structure of the cephalic end in the genus $\mathrm{Ci}$ thariniella Khalil, 1964 (Nematoda: Pharyngodonidae) as revealed by SEM, with a key to pharyngodonid genera from fishes. Syst. Parasitol. 27: 133-137.

Moravec F. 2009: Experimental studies on the development of Contracaecum rudolphii (Nematoda: Anisakidae) in copepod and fish paratenic hosts. Folia Parasitol. 56: 185-193.

Moravec F. 2013: Parasitic Nematodes of Freshwater Fishes of Europe. Revised Second Edition. Academia, Prague, $601 \mathrm{pp}$.

Moravec F., Justine J.-L. 2011: Cucullanid nematodes (Nematoda: Cucullanidae) from deep-sea marine fishes off New Caledonia, including Dichelyne etelidis n. sp. Syst. Parasitol. 78: 95-108.

Moravec F., Kohn A., Fernandes B.M.M. 1993: Nematode parasites of fishes of the Paraná River, Brazil. Part 2. Seuratoidea, Ascaridoidea, Habronematoidea and Acuarioidea. Folia Parasitol. 40: 115-134.

Moravec F., Van As J.G. 2004: Nematodes from the squeaker fishes Synodontis nigromaculatus and $S$. vanderwaali from the Okavango River, Botswana, including three new species. Syst. Parasitol. 59: 169-187.

Moravec F., Van As L.L. 2015a: Procamallanus (Procamallanus) spp. (Nematoda: Camallanidae) in fishes of the Okavango River, Botswana, including the description of $P$. (P.) pseudolaeviconchus n. sp. parasitic in Clarias spp. (Clariidae) from Botswana and Egypt. Syst. Parasitol. 90: 137-149.

Moravec F., Van As L.L. 2015b: Procamallanus (Spirocamallanus) spp. (Nematoda: Camallanidae) from fishes of the Okawango River, Botswana, including $P$. (S.) serranochromis $\mathrm{n}$. sp. parasitic in Serranochromis spp. (Cichlidae). Syst. Parasitol. 90: 151-164.

Moravec F., Van As L.L. 2015c: Studies on some spirurids (Nematoda: Spirurida) from fishes of the Okavango River, Botswana. Syst. Parasitol., in press. 
Ndew D.E., Diouf M., BÂ C.T., Morand S. 2014: A new species of Cucullanus (Nematoda: Cucullaninae, Cucullanidae) from Mugil curema (Mugilidae) in Senegal (West Africa). Comp. Parasitol. 81: 15-22.

Otachi E.O., Körner W., Avenant-Oldewage A., FellnerFrANK C., JiRsa F. 2014: Trace elements in sediments, blue spotted tilapia Oreochromis leucostictus (Trewavas, 1933) and its parasite Contracaecum multipapillatum from Lake Naivasha, Kenya, including a comprehensive health risk analysis. Environ. Sci. Pollut. Res. 21: 7339-7349.

PAPERNA I. 1974: Hosts, distribution and pathology of infections with larvae of Eustrongylides (Dioctophymidae, Nematoda) in fishes from East African lakes. J. Fish Biol. 6: 67-76.

Petter A.-J., Le Bel J. 1992: Two new species in the genus Cucullanus (Nematoda - Cucullanidae) from the Australian region. Mem. Inst. Oswaldo Cruz 87 (Suppl. I): 201-206.

Petter A.-J., Vassiliadès G., Troncy P.-M. 1972: Trois espèces d'oxyures parasites de poissons en Afrique. Ann. Parasitol. Hum. Comp. 47: 569-579.

Puylaert F.A. 1970: Description de Labeonema intermedia gen n., n. sp., parasite d'un Labeo (Pisces-Cyprinidae) (Atractidae Nematoda - Vermes). Rev. Zool. Bot. Afr. 82: 370-376.

Schuurmans Stekhoven J.H. 1937: Parasitic Nematoda. Exploration du Parc National Albert. Mission G.F. de Witte (19331935). Bruxelles 4: 3-40.
Sikoki F., Nzeako S., Nchege B. 2013: Evaluation of nematode parasitemia in Oreochromis niloticus from Lower New Calabar River, Port Harcourt, Niger Delta, Nigeria. Int. J. Sci. Res. Env. Sci. 1: 263-267.

Sprent J.F. 1982: Ascaridoid nematodes of South American mammals, with a definition of a new genus. J. Helminthol. 56: 275295.

Van Waerebeke D., Chabaud A.G., Bain O., Georges A.J. 1988: Deux nouveaux nématodes parasites de poissons de l'Oubangui. Bull. Mus. Natn. Hist. Nat., Paris, 4 sér., sect. A, 10: 519-527.

VASSILIADÈs G. 1975: Nématode parasites des poissons d'eau douce de la République du Sénégal. Bull. Inst. Fondam. Afr. Noire, Sér. A, 37: 605-618.

VAssiliadès G., Troncy P.-M. 1974: Nématodes parasites des poissons du bassin tchadien. Bull. Inst. Fond. Afr. Noire, Sér. A, 36: 670-681.

Von BRAnd T. 1944: Physiological observation upon a larval Eustrongylides. IV. Transmission to various coldblooded intermediate hosts. Proc. Helminthol. Soc. Wash. 11: 23-27.

Yooyen T., Moravec F., Wongsawad C. 2011: Two new species of Cucullanus Müller, 1777 (Nematoda: Cucullanidae) from marine fishes off Thailand. Syst. Parasitol. 78: 139-149.

Cite this article as: Moravec F., Van As L.L. 2015: Studies on ascaridid, oxyurid and enoplid nematodes (Nematoda) from fishes of the Okavango River, Botswana. Folia Parasitol. 62: 039. 